\title{
Gage Blocks of Superior Stability: Initial Developments in Materials and Measurement
}

\author{
M. R. Meyerson, T. R. Young, and W. R. Ney
}

(April 1, 1960)

\begin{abstract}
Increased demands on modern technology have established a requirement for gage blocks with higher accuracy of length calibration than is currently available. The desired improvement is tenfold and involves an increase in reliability from $2 \times 10^{-6}$ in./in. to 1 or $2 \times 10^{-7} \mathrm{in}$./in. The problem of achieving gage blocks dimensionally stable to this degree is fundamental and has two aspects; (1) the development of a suitable material and treatment to produce a gage block with the desired dimensional stability, surface quality, and several other physical properties, (2) the development of instrumentation and techniques for the precise measurement of temporal changes of length, so that stability of test samples may be determined to the required precision.

To date the program has been successful in developing three sets of gage blocks from two materials that have met the requirements and have shown a dimensional stability of $2 \times 10^{-7} \mathrm{in}$./in./yr over an observed period of one year. A technique for measurement based on the use of a mechanical-electronic comparator and a rigorous application of statistical control have supplied data precise to within $\pm 2 \times 10^{-7} \mathrm{in}$. The processes, technical aspects, and techniques involved in these developments are fully explained, and plans for further investigation and improvement are indicated.
\end{abstract}

\section{Introduction}

Gage blocks are precise representatives of the national standard of length maintained at the $\mathrm{Na}$ tional Bureau of Standards. As such they are in general use throughout industry and government for direct measurements or as standards for the calibration of measuring tools and other devices. Their sizes not only should be known and measurable to a high degree of precision, but once established, the sizes should remain within a desired constancy with the passage of time. Many instances are reported $[1,2,3]^{1}$ where hardened steel gage blocks have changed dimensions upon aging. This dimensional instability has been reported as a shrinkage, a growth, or even as a change from one to the other at different times of measurement.

Gage blocks purchased for governmental use are obtained in accordance with Federal Specification GGG-G-15, June 7, 1956. The standards of quality specified therein are also in general use throughout industry. The best steel gage blocks currently available are made to standards designated as AA, Laboratory Grade, Class 1, which provide for tolerances on lengths of $\pm 2 \times 10^{-6} \mathrm{in}$./in. on blocks longer than 1 in. and $\pm 2 \times 10^{-6}$ in. on blocks 1 in. or shorter. A minimum hardness of 65 Rockwell $\mathrm{C}\left(65 \mathrm{R}_{\mathrm{c}}\right)$ or equivalent on or adjacent to the wringing surface is required. The specification also contains allowable tolerances on flatness, parallelism, and finish of the wringing surfaces, but there are no quantitative requirements for dimensional stability; only the statement, ". . . suitably treated to assure dimensional stability of the finished gages."

Gage blocks are not used to measure to the extreme

1 Figures in brackets indicate the literature references at the end of this paper. limits of the indicated tolerances; a factor of ten is usually allowed to compensate in part for inaccuracies established by dimensional instability, wear, and the summation of errors formed in combining two or more blocks. With that criterion, current commercial blocks are used to measure no closer than $\pm 2 \times 10^{-5}$ in./in. With the advent of the space and atomic era, the need for measuring to \pm 1 or $2 \times 10^{-6} \mathrm{in}$./in. is anticipated by industry and recognized by the Congress of the United States. Such a degree of precision would necessitate gage blocks with a tolerance of \pm 1 or $2 \times 10^{-7} \mathrm{in}$./in. The development of gage blocks to meet this specification presents a dual problem of materials and measurement. Accordingly, the investigation was designed to study both facets of this problem and the cooperative efforts of personnel from two divisions of the National Bureau of Standards (Metallurgy, and Optics and Metrology) were applied. The Metallurgy Division was given the responsibility for the selection, development, treatment and evaluation of materials, and the Optics and Metrology Division for the development and improvement of measuring techniques and the determination of stability of experimental gage blocks. Several companies ${ }^{2}$ interested in the manufacture or application of gage blocks, are actively cooperating in the program and have supplied invaluable advisory service, the bulk of the blank materials used, all of the facilities and personnel for lapping, and a portion of the operating funds.

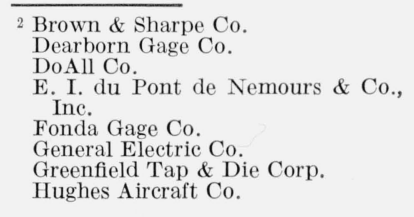

International Business Machines Corp.

Link Aviation, Inc.

Link Aviation, Inc.
New Departure Division of General Motors Corp.

Pratt \& Whitney Co., Inc.

Taft-Peirce Mfg. Co.

The Sheffield Corp.

The Timken Roller Bearing Co.

The Van Keuren Co. 
It was apparent from the onset that the program was to be a lengthy one which would require years to complete. Once suitable techniques for measuring blocks to one or two parts in ten million were developed, it would still require about eighteen months to manufacture a gage block to the required specifications, and obtain sufficient stability data to indicate a trend. Thus, gage blocks made in 1957 or 1958 and under observation since 1958 have just begun to produce significant data. As a result of these observations, additional gage blocks are being designed for improved performance, but these will not show results until the end of 1960 . In fact, any ideas developed in the program require about eighteen months to verify or disprove, and even then such a verification can be considered only as tentative pending observation over longer periods of time.

The purpose of this paper is to acquaint the reader with the scope of the entire program, to describe the materials and procedures being used to produce experimental gage blocks and the technical aspects involved, to describe the instrumentation and techniques developed to measure the gage blocks, and to present results on two of the selected materials which have been observed for stability sufficiently long to have produced significant trends.

\section{Previous Investigations}

The dimensional instability of hardened steel for gage blocks was described by Rolt [1] in 1929 and was recognized by Johansson and others prior to that time. In this country many excellent investigations have been concerned with the mechanism of instability of hardened steels and methods of alleviating the condition, notably the work of Scott [4], Cohen and his associates $[5,6,7,8,9,10]$ and Gippert and Butler [11]. As a result, hardened steel gage blocks undoubtedly can be made more stable today than they could many years ago, but more stringent requirements make further improvement necessary.

A set of gage blocks, said to be of uniform chemical composition and processed alike, was purchased in 1929 by the National Bureau of Standards from C. E. Johansson. These blocks were personally selected by Johansson for excellence of planeness, parallelism, surface finish and dimensional stability. The stabilizing treatment consisted of several cycles of annealing, hardening, tempering and a refrigeration treatment at $32^{\circ} \mathrm{F}$, although the exact mechanisms involved were not fully understood. Several gage blocks had also been purchased from the same source two vears earlier, in 1927 , and at that time were presumed to have a similar composition and to have been given the same heat treatment. These two lots of blocks have been observed for length changes since their procurement, and the results have been varied [2]. Some have a history of constant and large growth (up to $2 \times 10^{-5} \mathrm{in}$./in.), others have not varied more than $2 \times 10^{-6}$ in./in., and the rest have remained stable or have shrunk slightly for a period of one to seven years and then have proceeded to grow. Two of the more stable and two of the less stable blocks were independently analyzed for retained austenite at the Timken Roller Bearing Co. [12] and the National Bureau of Standards; the results of the two laboratories agreed closely. The two more stable blocks contained about 11 percent of retained austenite. The least stable of the four had 20 percent, and the other unstable block had 15 percent. These tests not only indicate the large variation in stability that may be obtained with what must be presumed to be very small variations of composition and/or treatment, but also the inadequacy of judging dimensional stability on the basis of short-time observations. These blocks also supply evidence that the presence of some retained austenite need not necessarily promote dimensional instability, and may in fact contribute to stability. Observations based on measurements of one year or less and which indicate a desirable degree of stability, while a favorable sign, cannot be interpreted as final. Conversely, an indication of instability during the first vear may portend further instability during future years, although the degree may change and exceptions have been noted.

Other observations of interest have also been reported. In individual blocks, rates of change in length have varied in different portions of the blocks so as to introduce uneveness to previously flat surfaces [13]. Several instances have been noted at the National Bureau of Standards and elsewhere, where the disturbance of a nongaging side surface by relapping or even by etching produced an immediate change in length. Such observations indicate the presence in hardened steel gage blocks, of a delicate balance of residual stresses that produces dimensional changes when disturbed.

The concern for the dimensional stability of hardened steel gage blocks has led to the pursuit of other methods of obtaining suitable materials. Rolt mentioned development work in England in the 1920's on unhardened gage blocks, coated with Stellite or electroplated iron or chromium. In more recent times development has been directed towards the use of stable carbides, such as tungsten or chromium, but these are considered to have an unfavorable coefficient of thermal expansion. Quartz single crystals have been considered frequently, but both the coefficient of thermal expansion and the thermal conductivity of quartz are too low to permit convenient use with most metals.

\section{Materials}

\subsection{Requirements}

a. Dimensional Stability and the Structural Relationship

Dimensional stability is a prime requirement for gage blocks, and stability is affected by structure and stresses within materials. All steels have a metastable structure when hardened to the $65 \mathrm{R}_{\mathrm{c}}$ specified for gage blocks. As such there is a tendency for the structure (mostly martensite) to reject carbon in the form of carbides and for the distorted 
tetragonal lattice to become cubic. These processes, one of the stages of tempering, occur with relative ease at elevated temperatures and with great difficulty and slowness at room temperature, but the forces promoting the decomposition of martensite are present and can be expected to cause a reduction in volume of the gage block whenever a degree of decomposition occurs, no matter how slight. Hardened steel frequently contains various quantities of a second structural phase, austenite, which had failed to transform to martensite during the quenching and subsequent tempering operations. This phase is also metastable and can transform to martensite or bainite upon aging at room temperature. Such a transformation contributes to an increase in volume, a growth of the gage block. Superimposed upon the possible structural changes are the dimensional changes caused by the relief of residual stresses. Residual stresses are present in hardened steel gage blocks as the result of at least three processes; those put into the block by the thermal gradients formed on heating and cooling, those formed as the result of structural changes, and those resulting from surfaces plastically strained in the fabricating processes. The relief of residual stresses can occur slowly at room temperature and can produce either a growth or shrinkage depending on the sign and orientation of the stresses. The ideal solution to the stabilization of a hardened steel block would be to treat it so that the shrinkage caused by the decomposition of martensite would be counteracted by the growth contributed by the transformation of austenite; and the balance of these changes compensated for in full by changes in the residual stress pattern. Such a solution is not belived entirely feasible with hardened steels, but with careful selection of suitable heat treatment and processing, it is hoped to reduce dimensional changes resulting from these factors to the desirable limits of $2 \times 10^{-7}$ in. $/ \mathrm{in} . / \mathrm{yr}^{3}{ }^{3}$

It was believed that the metastable structure alone was a severe deterrent to obtaining the degree of dimensional stability desired, and for that reason materials other than hardened steels were included in the progr $x \mathrm{~m}$. Nevertheless, the wide usage and popularity enjoyed by hardened steel gage blocks precluded the omission of these materials, and efforts were directed towards improving their performance characteristics.

A fully annealed steel is at or near its equilibrium condition. Provided all residual stresses are absent, it should be dimensionally as well as structurally stable. It was reasoned that a thin nitrided case applied to such a structure would produce an overall stable block with high surface hardness and wear resistance, even if the thin case should show some instability. The modulus of elasticity of steel is about the same whether the steel is annealed or

3 The addition of a time factor to the tolerance is not normally done in gage block usage, since a tolerance is the maximum permissible variation from a given size. However, in a discussion of stability, where absolute stability may be unattainable, it is necessary to affix a time parameter. The time increment selected, one year, also implies that the gage block need not be calibrated at more frequent intervals than 1 year. hardened, and the support given by a steel to its nitrided case is the same whether that steel is annealed or hardened, provided the elastic limit of the annealed steel is not exceeded. For the extremely mild service for which these ultra stable gage blocks are intended, an annealed core should be ample. The same reasoning was applied to types of hard surfacing treatment other than nitriding, and several have been considered including flame plating with tungsten carbide or aluminum oxide, chromium plating, and thermal spraying with nickel-chromium boron alloy.

\section{b. Other Required Characteristics and Properties}

Several other characteristics and properties are necessary or desirable in addition to dimensional stability. A high degree of surface finish, flatness of surfaces, and parallelism of opposite faces are required for precise measurements. These characteristics are related to the hardness and structure of the surfaces and their degree of development also depends on the skill of the final lappers. Ideally, the coefficient of thermal expansion, thermal conductivity, and other thermal properiies should be approximately equal to those of high carbon steel. The necessity of this value of the coefficient of expansion is often misunderstood, and frequently materials with zero or very low coefficients have been recommended. In actual application, a laboratory grade of gage block is most frequently used to calibrate other high carbon steel gage blocks or tools by a comparison technique. Precise temperature control is essential and both the gage block and the measured piece must be allowed to come to the same temperature. If there are very slight fluctuations in temperature or its measurement, similar coefficients may produce a compensation of the error. Otherwise the exact fluctuation and temperature as well as the exact coefficients involved must be known and appropriate mathematical computations made. With high carbon steel, a temperature discrepancy of only $0.03^{\circ} \mathrm{F}$ is sufficient to change length by $2 \times 10^{-7} \mathrm{in}$./in., which is equivalent to the desired maximum tolerance being sought in this investigation. Other thermal properties are not generally considered important factors, but in the development of the measuring techniques, they were found to have considerable significance (see discussion in section 5). Surface hardness and wear resistance are related conditions, although the relationship may not be as direct as is customarily believed. However, it is easier to obtain a good lapped surface on a hard material than on a soft one, and a block that wears excessively will not maintain its size after repeated wringings. The ability to wring well is a necessary requirement. This characteristic is a function of the quality of the surface and it may be related to the material. Resistance to atmospheric and fingerprint corrosion is desirable not only from the standpoint of appearance, but because the build-up of oxide films on gaging faces may cause a change in length and will produce a deterioration in wringing ability. 


\subsection{Selection and Application}

The chemical compositions of the materials selected for investigation are given in table 1 ; the hardness values and available pertinent physical properties are summarized in table 2 . The materials can be divided conveniently into three groups as follows:

1. Steels hardenable throughout by heat treatment - 52100 modified, W4, D2, and 'T15 modified.

2 . Steels readily amenable to surface hardening treatments $-1010,8620,304,410,420,17-4 \mathrm{PH}$ and Nitralloy 135 .

3. Materials other than steel-aluminum oxide and three forms of titanium carbide.

Some of the steels of group 2 are also hardenable, but without additional surface conditioning the final hardness obtained is too low for a gaging surface.

Several treatments have been applied to most of the materials. Thus, a total of 41 major combinations of materials and treatments are being investigated (table 3). For example, 8620 steel has been both pack and liquid carburized and has been carbonitrided to give three combinations. In addition there are some secondary variations in processing which are not reflected in the table, but are discussed later in the text or in an appropriate appendix. These consist of such items as differences in case thickness, grinding procedures, and in tempering or stress-relieving treatments.

Experimental blocks of only two steels, 52100 and 410 stainless, have been under observation for stability sufficiently long to have produced significant results. Data for these blocks were obtained from five major combinations on the 52100 steel and four on the 410 stainless. The 52100 steel was processed to produce five additional heat-treating variations, and one variation in grinding. Both directly quenched and martempered blocks were tempered to obtain a hardness of $65 \mathrm{R}_{\mathrm{c}}$ and also 62 and 60 $\mathrm{R}_{c}$, and one group was martempered in oil instead of $\mathrm{NaNO}_{3}-\mathrm{NaNO}_{2}$. One major combination on the 410 was also given a variation in processing. In those blocks receiving single stage gas nitriding, the cases on the nongaging faces of some were completely removed by grinding, whereas on others only the white layer was removed. All of the other materials are under observation or are in various stages of processing. Therefore, all further discussion will be limited to these two steels.

TABLE 1. Designation and chemical composition of the materials selected for investigation

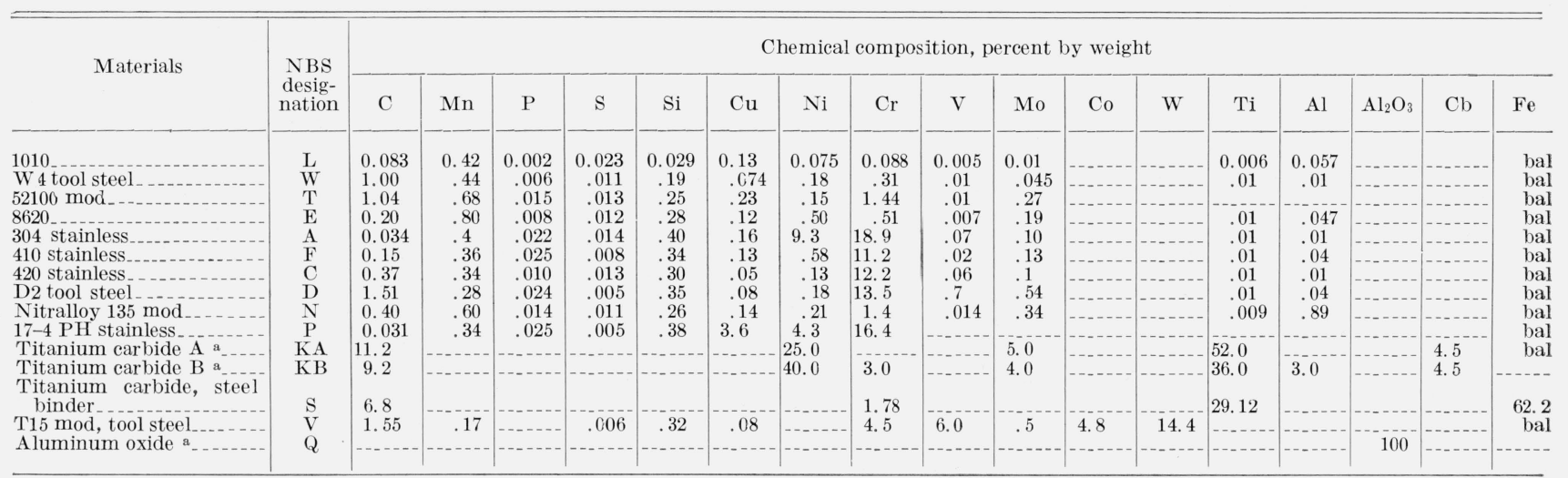

a Nominal composition supplied by the producer; all others were analyzed at NBS.

TABLE 2. Hardness and pertinent physical properties of the selected materials

\begin{tabular}{|c|c|c|c|c|c|c|}
\hline Materials & $\begin{array}{c}\text { NBS } \\
\text { designa- } \\
\text { tions }\end{array}$ & $\begin{array}{l}\text { Hardness, } \\
\text { annealed or } \\
\text { as received }\end{array}$ & Density & $\begin{array}{l}\text { Modulus of } \\
\text { elasticity }\end{array}$ & Coefficient of thermal expansion & Thermal conductivity \\
\hline $\begin{array}{l}\text { W4 tool steel } \\
52100\end{array}$ & $\begin{array}{c}\mathrm{E} \\
\mathrm{A} \\
\mathrm{F} \\
\mathrm{C} \\
\mathrm{D} \\
\mathrm{N} \\
\mathrm{P} \\
\mathrm{KA} \\
\mathrm{KB} \\
\mathrm{S} \\
\mathrm{V} \\
\mathrm{Q}\end{array}$ & $\begin{aligned} 87 & \mathrm{R}_{\mathrm{B}} \\
70 & \mathrm{R}_{\mathrm{B}} \\
83 & \mathrm{R}_{\mathrm{B}} \\
93 & \mathrm{R}_{\mathrm{B}} \\
95 & \mathrm{R}_{\mathrm{B}} \\
94 & \mathrm{R}_{\mathrm{B}} \\
29 & \mathrm{R}_{\mathrm{c}} \\
68 & \mathrm{R}_{\mathrm{c}} \\
72 & \mathrm{R}_{\mathrm{c}} \\
37 & \mathrm{R}_{\mathrm{c}} \\
98 & \mathrm{R}_{\mathrm{B}} \\
>70 & \mathrm{R}_{\mathrm{c}}\end{aligned}$ & $\begin{array}{l}l b / \mathrm{in}^{3} \\
0.284^{\mathrm{a}} \\
.283 \\
.283 \\
\\
\\
.283 \\
.29 \\
.280 \\
.278 \\
.277 \\
.280 \\
.228 \\
.217 \\
.305 \\
\end{array}$ & \begin{tabular}{l}
$p s i$ \\
$30 \times 10^{6}$ \\
30 \\
30 \\
\\
30 \\
29 \\
29 \\
32 \\
\hdashline 28 \\
\hdashline$-2-$ \\
57 \\
32
\end{tabular} & $\begin{array}{l}\quad \text { in. } / \text { in. } /{ }^{\circ} \mathrm{F} \\
6.5 \times 10^{-6}\left(68 \text { to } 212^{\circ}\right) \\
6.0\left(68 \text { to } 212^{\circ}\right) \\
6.3 \text { annealed }\left(85^{\circ}\right) \\
6.465 \mathrm{R}_{\mathrm{c}}\left(85^{\circ}\right) \\
6.462 \mathrm{R}_{\mathrm{c}}\left(85^{\circ}\right) \\
6.260 \mathrm{R}_{\mathrm{c}}\left(85^{\circ}\right) \\
6.6 \text { carbonitrided }\left(85^{\circ}\right) \\
9.0\left(85^{\circ}\right) \\
5.4 \text { annealed }\left(85^{\circ}\right) \\
5.7 \text { hardened }\left(85^{\circ}\right) \\
5.7 \text { hardened }\left(85^{\circ}\right) \\
6.5 \text { nitrided }\left(85^{\circ}\right) \\
6.0 \text { annealed }\left(70 \text { to } 200^{\circ}\right) \\
6.0 \\
5.3 \\
6.85\left(70 \text { to } 1300^{\circ}\right) \\
5.4\left(85^{\circ}\right) \\
3.0\left(85^{\circ}\right)\end{array}$ & $\begin{array}{l}.0313\left(212^{\circ}\right) \\
.0480\left(212^{\circ}\right) \\
.0443\left(390^{\circ}\right) \\
.0482\left(30^{\circ}\right) \\
.0344\left(300^{\circ}\right) \\
.0770\left(212^{\circ}\right) \text { est. } \\
.0770\left(212^{\circ}\right) \text { est. } \\
.0497\left(32 \text { to } 1020^{\circ}\right)\end{array}$ \\
\hline
\end{tabular}

a Italics indicate values obtained from published data, or private communication with manufacturer. All others were obtained at NBS. 
TABLE 3. Summary of treatments used for the selected materials

\begin{tabular}{|c|c|c|c|c|c|c|c|c|c|c|c|c|c|c|}
\hline \multirow{3}{*}{ Materials } & \multirow{3}{*}{$\begin{array}{c}\text { NBS } \\
\text { desig- } \\
\text { nations }\end{array}$} & \multicolumn{13}{|c|}{ Treatments } \\
\hline & & \multicolumn{2}{|c|}{ Harden } & \multicolumn{3}{|c|}{ Carburize } & \multicolumn{3}{|c|}{ Nitride } & \multicolumn{4}{|c|}{ Hard coat } & \multirow[b]{2}{*}{$\begin{array}{c}\text { As } \\
\text { manu- } \\
\text { factured }\end{array}$} \\
\hline & & $\begin{array}{c}\text { Direct } \\
\text { quench, } \\
\text { stabilize }\end{array}$ & $\begin{array}{c}\text { Mar- } \\
\text { temper, } \\
\text { stabilize }\end{array}$ & $\begin{array}{l}\text { Pack or } \\
\text { gas, } \\
\text { harden, } \\
\text { stabilize }\end{array}$ & $\begin{array}{l}\text { Liquid, } \\
\text { harden, } \\
\text { stabilize }\end{array}$ & $\begin{array}{l}\text { Carbo- } \\
\text { nitride, } \\
\text { harden, } \\
\text { stabilize }\end{array}$ & $\begin{array}{l}\text { Gas, } \\
\text { one } \\
\text { stage }\end{array}$ & $\begin{array}{c}\text { Gas, } \\
\text { two } \\
\text { stage }\end{array}$ & Liquid & $\begin{array}{c}\text { Ther- } \\
\text { mal- } \\
\text { sprayed } \\
\text { Ni-Cr-B }\end{array}$ & $\begin{array}{l}\text { Flame- } \\
\text { plated } \\
\text { tungsten } \\
\text { carbide }\end{array}$ & $\begin{array}{l}\text { Flame- } \\
\text { plated } \\
\mathrm{Al}_{2} \mathrm{O}_{3}\end{array}$ & $\begin{array}{c}\text { Electro- } \\
\text { plated } \\
\mathrm{Cr}\end{array}$ & \\
\hline $\begin{array}{l}1010 \\
\text { W4 tool steel } \\
52100 \\
8620\end{array}$ & $\begin{array}{l}\mathrm{L} \\
\mathrm{W} \\
\mathrm{T} \\
\mathrm{E} \\
\mathrm{A}\end{array}$ & $\begin{array}{l}\mathrm{X} \\
\mathrm{X}\end{array}$ & $\begin{array}{l}\mathrm{X} \\
\mathrm{X}\end{array}$ & $\begin{array}{c}\mathrm{X} \\
\mathrm{X}\end{array}$ & $\begin{array}{c}X \\
X\end{array}$ & $\begin{array}{c}\mathrm{X} \\
\mathrm{X}\end{array}$ & $\mathrm{X}$ & & $\mathrm{X}$ & $\begin{array}{l}\mathrm{X} \\
\mathrm{X} \\
-\cdots\end{array}$ & $\frac{\mathrm{X}}{\mathrm{X}}$ & X & $\frac{X}{x}$ & י \\
\hline $\begin{array}{l}410 \text { stainless } \\
420 \text { stainless } \\
\text { D2 tool steel } \\
\text { Nitralloy } 135 \\
17-4 \text { PH stainless }\end{array}$ & $\begin{array}{l}\mathrm{F} \\
\mathrm{C} \\
\mathrm{D} \\
\mathrm{N} \\
\mathrm{P}\end{array}$ & $\mathrm{X}$ & & & & & $\begin{array}{l}\mathrm{X} \\
\mathrm{X} \\
\mathrm{X} \\
\mathrm{X} \\
\mathrm{X}\end{array}$ & $\mathrm{X}$ & $\mathrm{X}$ & 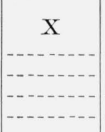 & $\frac{X}{X}$ & $\frac{X}{X}$ & $\frac{X}{X}$ & 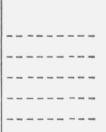 \\
\hline $\begin{array}{l}\text { Titanium carbide A\&B } \\
\text { Titanium carbide, steel } \\
\text { binder }\end{array}$ & $\begin{array}{c}\mathrm{KA} \& \mathrm{~KB} \\
\mathrm{~S}\end{array}$ & $\mathrm{X}$ & & & & & & & & & & & & $\mathrm{X}$ \\
\hline $\begin{array}{l}\text { T15 tool steel } \\
\text { Aluminum oxide }\end{array}$ & $\begin{array}{l}\mathrm{V} \\
\mathrm{Q}\end{array}$ & $\mathrm{X}$ & & & & & & & & & & & & $\bar{X}$ \\
\hline
\end{tabular}

Type 52100 steel is being used in this program principally, but not in every instance, as a throughhardened steel (group 1). It was selected for a prominent place in the program because it is widely used as a gage block material and for many kinds of tools and precision devices. Preliminary hardenability tests with a standard composition indicated failure to harden completely through with an oil quench in the size section required for this investigation. To obtain improved hardenability, a 52100 steel modified by the addition of 0.3 percent molybdenum was specified. A few blocks of 52100 were also employed in the annealed condition in an attempt to obtain improved stability and a coefficient of thermal expansion more favorable than that obtainable with the 410 stainless. A variety of hard coatings was applied to produce a suitable wear resistant surface.

Stainless steel, type 410 , is a martensitic type of stainless with relatively low hardness after hardening, but it possesses several properties of interest for gage block application. In the annealed condition it has essentially a single phased structure (except for spheroidal carbides) with its elements in solid solution. Its surface can be hardened by nitriding and it has good resistance to atmospheric corrosion, either when annealed or hardened. Its major apparent deficiency is a coefficient of thermal expansion reasonably close to but slightly lower than high carbon steel. Nitriding was the principal process used to harden the surfaces of the 410 , but the other treatments indicated in table 3 were also applied.

\section{Procedures for Processing and Fabrication}

\subsection{As Received Steels}

Each type of steel was obtained from a single heat and was commercially made in accordance with the accepted practices for that type, so that it would represent typical steels available on the market.
With the exception of the T15 and 17-4 PH steels, each was hot rolled by the manufacturer into rectangular bars $11 / 2$ in. $X 1 / 2$ in. After hot rolling and straightening, all bars were fully annealed by the manufacturer and precautionary measures taken to hold decarburization to a minimum. The gage blocks made from these bars were rectangular parallelepipeds with a gaging length of 2 in. and other dimensions of $1 \frac{3 / 8}{\text { in. }} \times \frac{3}{8}$ in.

The typical microstructures of the 52100 as annealed and after hardening and the 410 as annealed are shown in figure 1.

\subsection{Heat Treating of 52100 Steel}

With hardened steels, the difficulty of completely balancing the dimensional changes occurring from structural transformations against residual stresses can be minimized by keeping these factors at low levels. As a starting point, it was decided to eliminate almost all of the retained austenite, which would reduce the possibility of growth and provide data on the stability characteristics of an austenite-free steel, and would possibly give a higher hardness and allow a higher tempering temperature or longer time at temperature to obtain a final hardness of $65 \mathrm{R}_{\mathrm{c}}$. The higher tempering temperature was considered beneficial in the reduction of residual stresses. The standard procedure used for hardening by direct quench was to austenitize at $1550^{\circ} \mathrm{F}$ for $15 \mathrm{~min}$ and quench to room temperature in a quenching oil having an accelerated cooling rate.

The residual stresses resulting from thermal gradients on cooling from the hardening temperature are often reduced by martempering. The martempering treatment adopted consisted of austenitizing in a chloride bath at $1550^{\circ} \mathrm{F}$ for $15 \mathrm{~min}$, quenching in a sodium nitrate-nitrite bath at $300^{\circ} \mathrm{F}$ for $30 \mathrm{sec}$, and then quenching to room temperature in oil. 

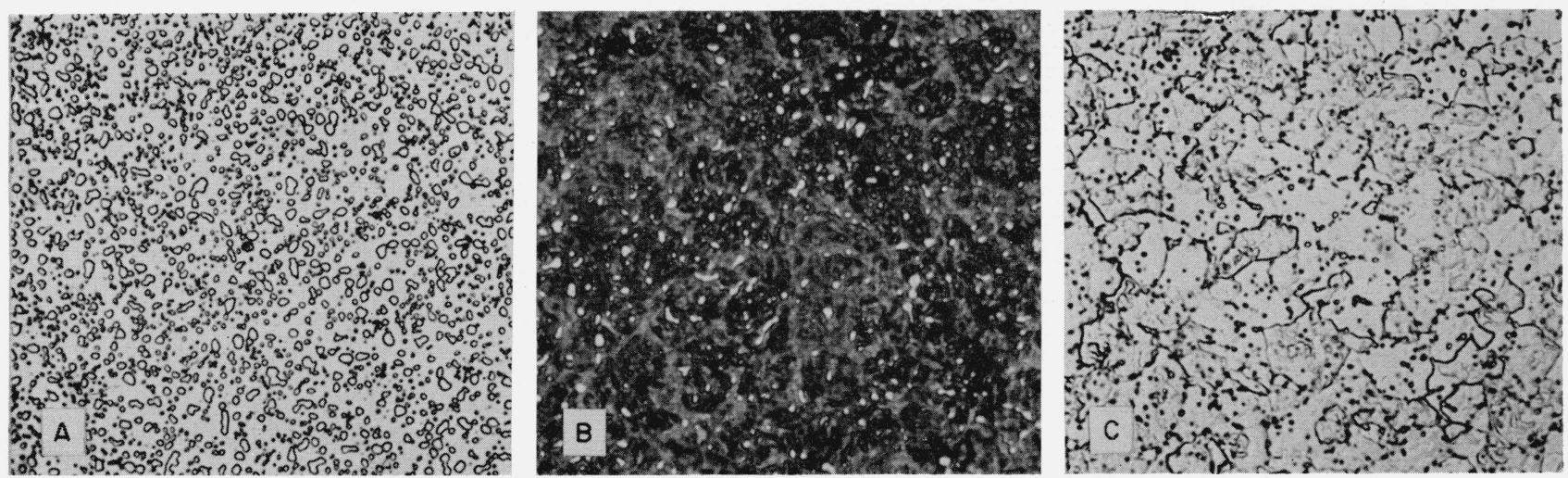

FigURE 1. Microstructure of 52100 and 410 stainless steel. $\times 750$

A. 52100, annealed, etched with $1 \%$ Nital.

B. 52100 , hardened, etched with $1 \%$ Nital.

C. 410 stainless, annealed, etched with hydrochloric + picric acids in ethano!

Both of the above hardening treatments were followed by a stabilization treatment designed to remove retained austenite, temper the martensite, and reduce residual stresses. This treatment for blocks hardened to $65 \mathrm{R}_{\mathrm{c}}$ consisted of an immediate refrigeration at $-140^{\circ} \mathrm{F}$ for an overnight period (18 to $22 \mathrm{hr}$ ), followed by a tempering treatment at $250^{\circ} \mathrm{F}$ for $1 \mathrm{hr}$, a second refrigeration treatment at $-140^{\circ} \mathrm{F}$ for an overnight period, and a final temper at $250^{\circ} \mathrm{F}$ for $9 \mathrm{hr}$. The interval between steps was kept as short as possible. Details of the investigation performed to establish this stabilization treatment as an optimum for the 52100 steel are given in appendix A.

The temperature of the final temper was raised in some instances where a hardness of less than 65 $R_{c}$ was desired. The prescribed hardness of $65 R_{c}$ is believed to have been an arbitrary selection to obtain good wear resistance, and it was thought that a block with slightly lower hardness such as 62 or $60 \mathrm{R}_{\mathrm{c}}$ might be satisfactory from a wear standpoint and possess greater stability. Details of the heat and stress relieving treatments given individual blocks, and the final hardness of each, are shown in table 4. A stress relieving treatment was applied to all gage blocks after finish machining and prior to final lapping.

\subsection{Nitriding of 410 Stainless Steel}

The 410 stainless was the first of the group 2 materials (steels readily amenable to surface hardening treatments) studied. The 410 steel was to be used in the annealed condition only, with the surface nitrided or otherwise hardened. The details of nitriding and stress relieving of each block are given in table 4 .

Tests were run to establish suitable procedures for nitriding this steel. No unusual techniques were required for effective nitriding. The surfaces of the blocks were prepared by grinding and thereafter were scrubbed in an aqueous detergent just prior to nitriding. A nitriding time of 40 to $44 \mathrm{hr}$ at 1010 to
TAвLE 4. The heat treatment and hardness of gage blocks a

\begin{tabular}{|c|c|c|c|c|c|}
\hline $\begin{array}{c}\text { Gage } \\
\text { block } \\
\text { no. }\end{array}$ & $\begin{array}{l}\text { Method of harden- } \\
\text { ing }\end{array}$ & $\begin{array}{l}\text { Final temper, } \\
9 \mathrm{hr},{ }^{\circ} \mathrm{F}\end{array}$ & $\begin{array}{l}\text { Stress relief, } \\
3 \mathrm{hr},{ }^{\circ} \mathrm{F} \mathrm{b}\end{array}$ & $\begin{array}{l}\text { Date of final } \\
\text { stress relief }\end{array}$ & $\begin{array}{c}\text { Hard- } \\
\text { ness } \\
\mathrm{R}_{\mathrm{e}^{\mathrm{c}}}\end{array}$ \\
\hline $\mathrm{T}-301$ & $\begin{array}{l}\text { Flame plate, } \\
\text { tungsten carbide. }\end{array}$ & Not applicable & 975 & May 1957 & 72 \\
\hline $\mathrm{T}-302$ & $\begin{array}{l}\text { Flame plate, } \\
\text { tungsten carbide. }\end{array}$ & Not applicable & 975 & May 1957 & 72 \\
\hline $\mathrm{T}-309$ & $\begin{array}{l}\text { Thermal spray, } \\
\text { Ni-Cr-B. }\end{array}$ & Not applicable & 975 & July 1957 & 62 \\
\hline T-312 & $\begin{array}{l}\text { Thermal spray, } \\
\text { Ni-Cr-B. }\end{array}$ & Not applicable & 975 & July 1957 & 62 \\
\hline T-314 & Elcctroplate, $\mathrm{Cr}_{--}$ & Not applicable & $400(5 \mathrm{br})$ & Jan. 1958 & 68 \\
\hline T-318 & Electroplate, $\mathrm{Cr}_{\ldots}$ & Not applicable & $400(5 \mathrm{hr})$ & Jan. 1958 & 68 \\
\hline $\mathrm{T}-337$ & Martemper........ & $250 \mathrm{e}$ & 240 & Jan. 1958 & 65 \\
\hline $\mathrm{T}-341$ & Martemper ....... & 250 e & 240 & Jan. 1958 & 65 \\
\hline $\mathrm{T}-343$ & Direct quench ... & 250 & 240 & Jan. 1958 & 65 \\
\hline $\mathrm{T}-344$ & Direct quench & 250 & 24 & Jan. 1958 & 65 \\
\hline $\mathrm{T}-348$ & Direct quench & 250 & 240 & Jan. 1958 & 65 \\
\hline $\mathrm{T}-351$ & Martemper & 350 & 340 & Jan. 1958 & 62 \\
\hline T-356 & Martemper. & 350 & 340 & Jan. 1958 & 62 \\
\hline $\mathrm{T}-357$ & Martemper & 45 & 44 & Feb. 1958 & 60 \\
\hline $\mathrm{T}-359$ & Martemper...... & 450 & 440 & Feb. 1958 & 60 \\
\hline $\mathrm{T}-369$ & Martemper (oil) & 250 & 240 & Feb. 1958 & 65 \\
\hline $\mathrm{T}-377$ & Direct quench & 350 & $340(4 \mathrm{hr})$ & May 1958 & 62 \\
\hline $\mathrm{T}-378$ & Direct quench & & $340(4$ & May 1958 & 61 \\
\hline $\mathrm{T}-3 \varepsilon 4$ & Direct quench... & $475(23 \mathrm{hr})$ & $465(4 \mathrm{rr})$ & May 1958 & 59 \\
\hline$T-386$ & Direct quench... & $47523 \mathrm{hr})$ & $465(4 \mathrm{hr})$ & May 1958 & 59 \\
\hline F-302 & Nitride_ & Not applicable d & 975 & Mar. 1957 & 67 \\
\hline $\mathrm{F}-305$ & Nitride & & 97 & Mar. 1957 & 70 \\
\hline $\mathrm{F}-316$ & $\begin{array}{l}\text { Flame Plate, } \\
\text { tungsten carbide. }\end{array}$ & & 975 & May 1957 & 72 \\
\hline F -317 & $\begin{array}{l}\text { Flame plate, } \\
\text { tungsten carbide. }\end{array}$ & & 975 & May 1957 & 72 \\
\hline $\mathrm{F}-322$ & Nitride, 2 stage & & 975 & Mar. 1957 & 67 \\
\hline $\mathrm{F}-323$ & Nitride, 2 stage & & 975 & Mar. 1957 & 67 \\
\hline $\mathrm{F}-325$ & Nitride, 2 stare & & 975 & Mar* 1957 & 65 \\
\hline $\mathrm{F}-327$ & Nitride, 2 stage & & 975 & Mar. 1957 & 67 \\
\hline $\mathrm{F}-330$ & Nitride_. & & 975 & Apr. 1957 & 65 \\
\hline & Nitride_... & & 975 & Apr. 1957 & 69 \\
\hline $\mathrm{F}-340$ & Nitride & & 975 & Apr. 1957 & 67 \\
\hline F-349 & Nitride_......... & & 975 & July 1957 & 72 \\
\hline $\mathrm{F}-352$ & Electroplate, $\mathrm{Cr}_{-}$ & & $400(5 \mathrm{hr})$ & Jan. 1958 & 68 \\
\hline & Electroplate, $\mathrm{Cr}_{\ldots}$ & & $400(5 \mathrm{hr})$ & Jan. 1958 & 68 \\
\hline $\mathrm{F}-360$ & Nitride & & 975 & July 1957 & 67 \\
\hline $\mathrm{F}-361$ & Nitride & & 975 & July 1957 & 69 \\
\hline $\mathrm{F}-363$ & Nitride_.......... & & 975 & July 1957 & 69 \\
\hline
\end{tabular}

a All gage blocks were nominally 2 in. $\times 13 / 8$ in. $\times 3 / 8$ in.

b Stress relief was applied to all gage blocks after finish machining and prior to b Stress relief
final lapping.

c This value represents hardness of the case or coating where applicable. Where appropriate, hardness was measured with a micro tester such as the Vickers and converted to $\mathrm{R}$

d This applies from F-302 through F-363.

e The length of time held at final temper is uncertain. 
$1030^{\circ} \mathrm{F}$ produced a case about $0.009 \mathrm{in}$. thick. Dissociation of the ammonia was maintained at 20 to 25 percent. As the result of nitriding, the blocks grew different amounts in each of the three directions; on the order of $0.0025 \mathrm{in}$. in the $2 \mathrm{in}$. dimension, 0.0020 in. in the $1 \frac{3}{8}$ dimension, and $0.0015 \mathrm{in}$. in the $3 / 8$ in. dimension.

The two stage Floe process was also employed in an attempt to reduce or eliminate the white layer formed with conventional single stage nitriding. In this process, the first step consisted of nitriding for 20 to $24 \mathrm{hr}$ at $1000^{\circ} \mathrm{F}$ with a dissociation of 20 to 25 percent. Thereafter, the temperature of the retort was raised to $1050^{\circ} \mathrm{F}$ and cracked ammonia blended with the uncracked ammonia to give a dissociation of 75 to 80 percent. The second stage was maintained for about $24 \mathrm{hr}$.

The microstructures of a nitrided case produced by the single stage method are shown in figure 2 . The hardness of the case nitrided by the single stage process exceeded 1260 KHN (Knoop Hardness Number, $200 \mathrm{~g}$ load) over its entirety. The hardness of the case produced with the two stage process was somewhat less than the case formed with single stage nitriding. Immediately adjacent to the surface the hardness was $880 \mathrm{KHN}$, the greater portion of the case had a hardness of $1020 \mathrm{KHN}$, and next to the core, hardness fell to $930 \mathrm{KHN}$ (500 $\mathrm{g}$ loads). All of these values are appreciably greater than the minimum of $65 \mathrm{R}_{\mathrm{c}}$ specified for gaging surfaces.

In the grinding and lapping operations applied to the gaging surfaces after nitriding, approximately 0.0025 in. was removed, which left from 0.006 in. to $0.007 \mathrm{in}$. of the case. The finish produced on the nitrided 410 blocks by commercial lapping is worthy of note. It was superior to finishes produced on hardened 52100 steel, but took about one third more time for the removal of equivalent amounts of stock. The final microfinish, as measured with a tracertype surface roughness instrument, closely approached zero. Wringing characteristics were excellent. An interferogram of the surface of one of these blocks and a photograph of the surface of another is shown in figure 3 . There was a sharp interface and an intermediate zone of nitrogen diffusion becween the case and the core (fig. 2), which was unlike the gradual blending associated with the nitrided case of Nitralloy. This type of interface is generally believed to be a plane of weakness in the steel and a region where spalling can occur easily. After removal of the white layer, several blocks were subjected to rough handling, including severe grinding and impact deformation of lapped surfaces, and no spalling occurred. The mild mechanical service to which this type of gage block should be subjected further reduces the possibility of trouble from spalling.

The corrosion resistance of the case is different from that of the original steel. As can be seen from the microstructure in figure 2 , dilute nitric acid and Vilella's reagent attack the nitrided layers more readily than the ferritic matrix. On the other hand, the nitrided surfaces are less subject to coating by tinted surface films in such processes as stress reliev- ing in a cracked ammonia atmosphere. Nitrided and lapped surfaces with no protective wrapping, oil or wax film, or other corrosion preventive treatments have been exposed for two years under normal indoor conditions of humidity and temperature in the atmosphere of Washington, D.C., and have shown no tendency to become dull or to rust.

The single stage nitriding treatment was applied to two series of blocks that were fabricated differently after nitriding. In one series the nitrided layer was completely removed from the four nongaging faces by grinding parallel to the $2 \mathrm{in}$. dimension. In the other series, only about 0.002 in. was ground from each nongaging surface so as to produce a bright nitrided finish. The first series, as a result, was finished with nitrided cases on the two gaging faces only, while the second series had nitrided cases all over.

In a third series, the blocks were nitrided by the two stage process, and the four nongaging surfaces were not ground or otherwise disturbed after nitriding.

\subsection{Hard Coatings}

Both the 52100 and the 410 stainless were coated with hard-facing materials in four different ways: 1, Thermal spraying with a nickel-chromium-boron alloy; 2, flame plating with tungsten carbide; 3 , flame plating with aluminum oxide; 4, electroplating with chromium. In each instance the base material was in the annealed condition. The stability of the 410 stainless thermally sprayed with nickelchromium-boron is not reported in this paper because the blocks required additional shortening and the final lapping has not been completed. No report is made on these two steels flame plated with aluminum oxide because of the difficulties of obtaining a good interferometric fringe pattern on this surface. The same difficulties were not experienced on blocks of solid aluminum oxide incorporated into the measuring program at a later date. Details of each coating and the methods of application are given in appendix B. Subsequent stress relief treatments and the final hardness of each coating are given in table 4 .

\subsection{Fabrication}

The hardening and stabilization of the 52100 steel, the nitriding of the 410 stainless, and the chromium electroplating were carried out in laboratories of the National Bureau of Standards. Thermal spraying of nickel-chromium-boron alloy and flame plating with tungsten carbide were applied by commercial firms. All machining operations except lapping were performed in the Bureau's machine shop. Lapping was done by several commercial firms ${ }^{4}$ in accordance with the best commercial practices. The procedures for grinding and other details of fabrication are given in appendix C. Considerable care was exercised in fabricating these blocks and recording the details thereof, because of the potential significance attributed to residual stress patterns induced bv these processes.

${ }^{4}$ Brown \& Sharpe Co., Dearborn Gage Co., DoAll Co., and Pratt and Whitney Co., Inc. 


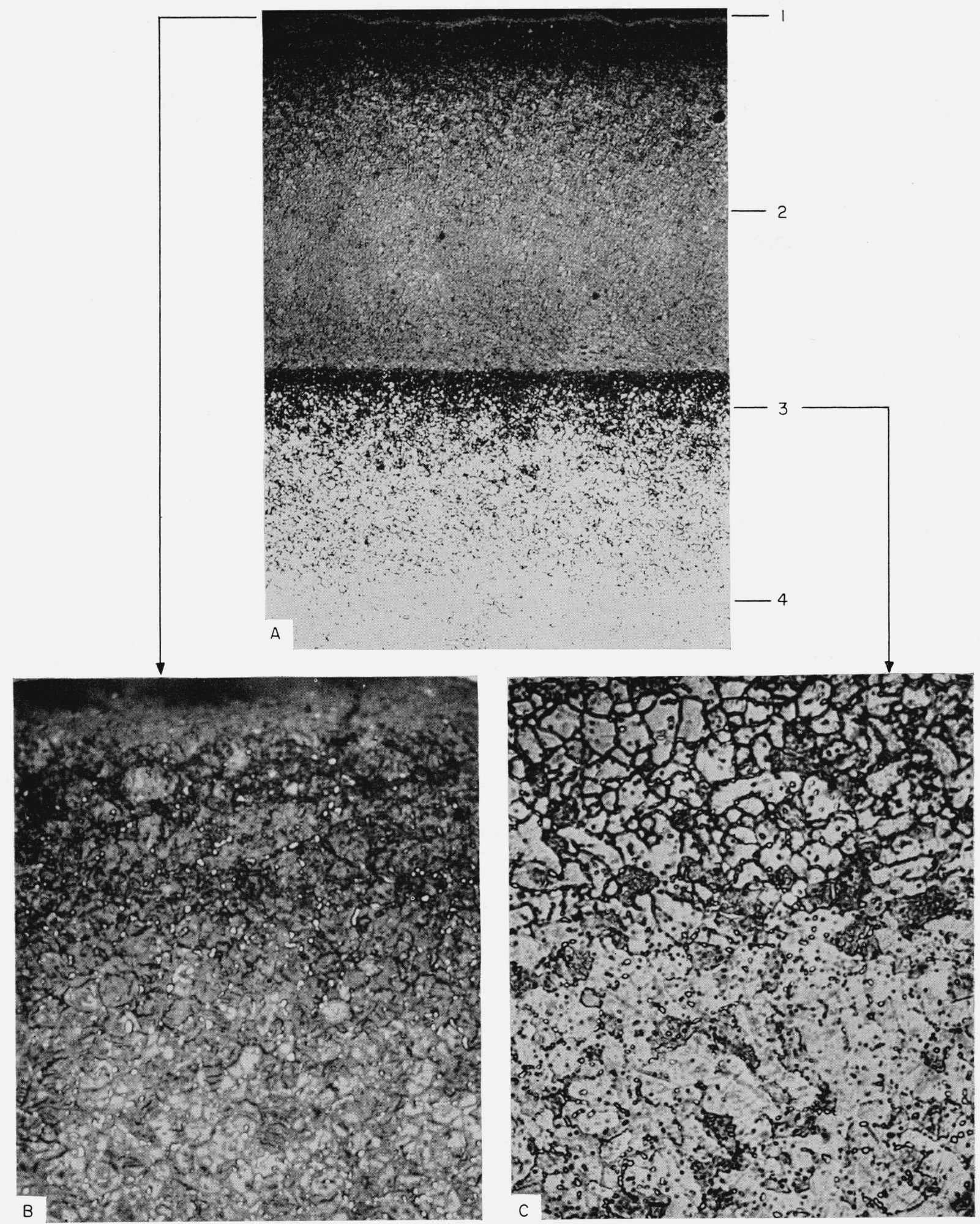

FiguRE 2. Microstructure of nitrided 410 stainless steel.

Dual etch: $1 \%$ Nital followed by Vilella's Reagent.

A. 1. White layer; 2. Nitrided case; 3 . Intermediate zone: 4 Core; $\times 250$.

B. Case. White layer is at the top and appears gray with etchants used. $\times 1000$.

C. Intermediate zone and core. $\times 1000$. 


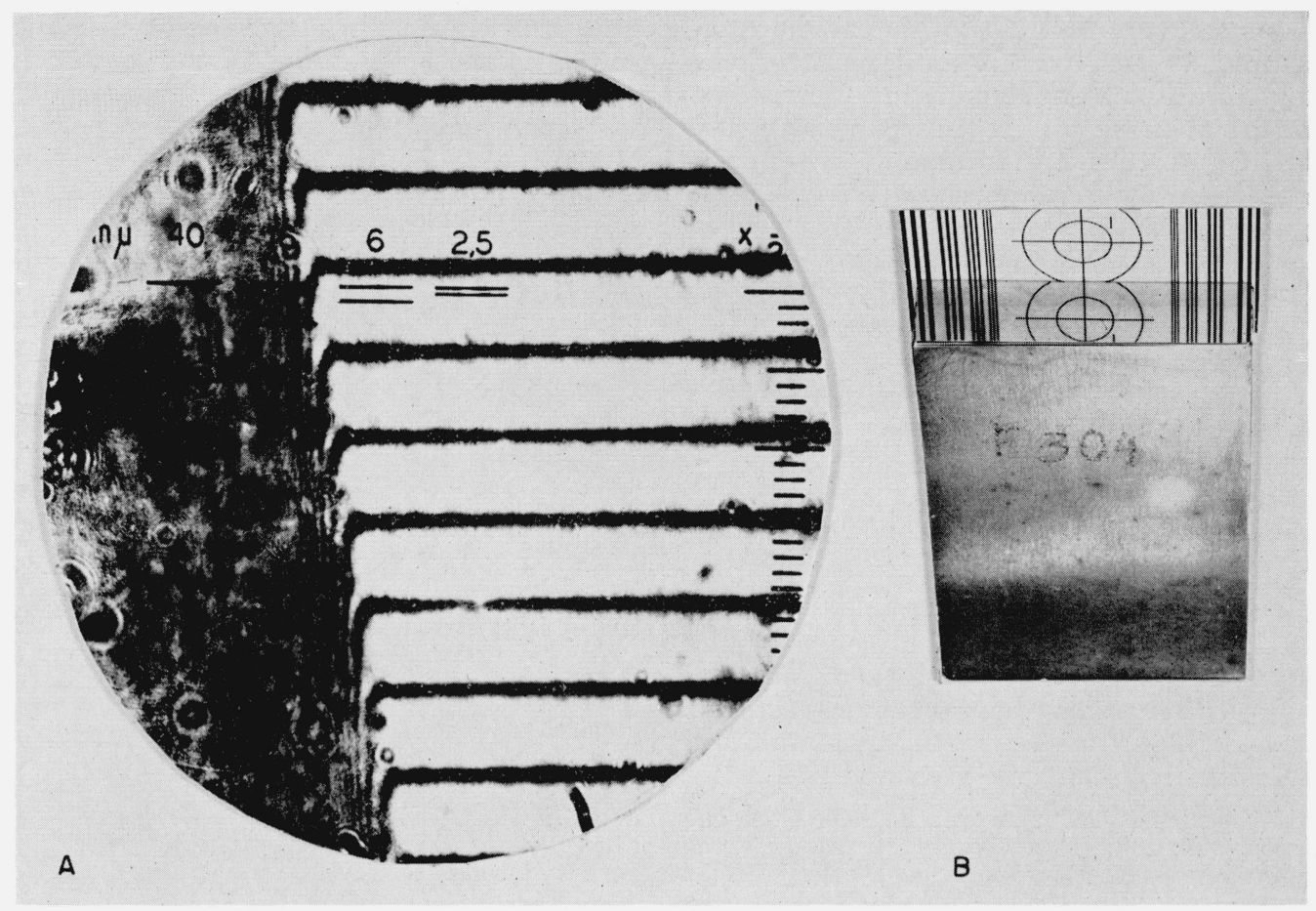

FIGURE 3. Nitrided surfaces on initially annealed 410 stainless steel.

A. Interferogram (courtesy the DoAll Co.). The interference fringe interval is about $250 \mathrm{~m} \mu$.

B. Reflection frcm mirror-like surface. The form of chart has no significance other than to provide an image for reflection.

\section{Metrology}

\subsection{Development of the Measuring Technique}

The measurement phase of the stability program required a testing technique that would provide frequent measurements of a large number of test samples and precision of length measurement on the order of 2 parts in 10 million.

The degree of precision would determine the time interval required to acquire significant data indicating change of length of the test samples. Frequent measurements would provide information on the nature of the change. As the test samples are 2 in. in length, a practical limitation to the error of measurement of $0.4 \mu$ in. was established as a goal $(0.2 \mu$ in./in. $)$.

To establish the change in length of the test samples it was necessary to define a length scale whose stability characteristics were known. An ideal procedure would be to compare the sample with a length scale formed by the interference of light of known wavelength. It is generally believed that a wavelength of light, $\lambda$, is constant in time and may be expressed by

$$
\lambda=\frac{c}{\mu \nu}
$$

where $c$ is the velocity of light in vacuum,

$\mu$ is the index of refraction of the material through which the light is transmitted,

$\nu$ is the frequency of light radiation.
Procedures and instrumentation are available that provide such absolute measurements of the test samples [14]. Although the Bureau is now engaged in the development of procedures and instrumentation to achieve precision in such absolute measurements to 1 or 2 parts in 10 million, the best that could be done when the stability program was initiated was 1 part in 1 million.

The precision of such measurements is limited by the differing effects of temperature on the sample and the interference scale formed in the air surrounding the sample. The index of refraction of air is dependent upon temperature, so from the equation it is observed that the wavelength of light is dependent upon temperature. For visible light in an approximate standard atmosphere $\left(760 \mathrm{~mm} \mathrm{Hg}, 68^{\circ} \mathrm{F}\right)$, the wavelength scale might be considered as having a coefficient of expansion approximately 1/10 that of steel, which was the material used for most of the stability samples. In addition, problems are encountered if the temperature of the measurement area is not stable. Because of thermal lag, the temperature of the air in which the wavelength scale is formed will, in general, be different than the temperature of the sample. For example, Evans [15] reports the thermal lag time of a polished iron cylinder of $2 \mathrm{~cm}$ diam immersed in air to be 2,000 sec., causing the axial temperature of the rod to differ from air by $1.0^{\circ} \mathrm{F}$ when the temperature of the air is increasing $1.8^{\circ} \mathrm{F}$ per hour. Thus the relationship between the sample and the wavelength scale is critically dependent upon temperature, and 
the effective temperature of the sample can be difficult to determine as the axial temperature of the sample is likely to differ from its surroundings.

One method of avoiding difficulties of this nature is to resort to comparison measurements where the length of the test sample is compared with a standard length having thermal properties similar to those of the sample. A specially designed optical interference comparator [16] of a type originally developed by Kösters [17] was available that could be relied upon to provide precision to approximately 1 part in 10 million. As most of the test samples were steel blocks $1 \frac{3 / 8}{8}$ in. $\times \frac{3}{8}$ in. $\times 2$ in. long, it was considered highly desirable to select as a standard of length a steel gage block with the same cross sectional size and nominal length and having a long history of absolute length measurements to indicate stability.

Absolute measurements made at irregular periods since January 1954 on a 2 in. steel gage block serving as a length standard for the NBS Engineering Metrology Section indicated it to be exceedingly stable. The curve best fitting the measurement data indicated that its growth had not exceeded $0.2 \mu$ in. since the measurement series began. This gage block was chosen as the basic reference length for the stability measurement program. Since the initiation of the program this block has been subjected to more frequent absolute length measurements. These recent measurements continue to justify its choice as a stable standard.

The difficulty encountered in using the interference comparator as the measuring instrument was an insufficient testing capacity to measure all the test samples as frequently as desired. For test samples of $2 \mathrm{in}$. length, a minimum time of $4 \mathrm{hr}$ is considered necessary between the operation of wringing the test specimen to the platen and the comparison of this specimen with the master gage block. This interval is believed necessary to allow the test specimen to attain thermal equilibrium with the master block and to allow the wringing film to attain its minimum thickness in case more wringing lubricant is used than is necessary. During this time interval, it is necessary to maintain the platen in the location occupied during the measurement. Thus, the need for this time interval limited the test capacity of the interferometer.

During the initial months of investigation of any specimen, it was desired that its length be determined weekly. Thus it was foreseen that a test program having a capacity of 50 measurements a week was required. The classical methods of precise length comparison rely upon the comparison of static lengths and are time consuming because they require thermal equilibrium. The most apparent solution to the problem of increasing test capacity was to abandon the concept of static length comparisons and replace it with the concept of dynamic length comparisons. In general, such comparisons had not been reined to a degree giving the precision that was required. It was questionable whether the instrumentation usually employed in such comparisons would provide the necessary repeatability.
Figure 4 indicates schematically a typical mechanical comparator employed in dynamic length comparisons. The measuring styluses are mounted in reed spring systems to avoid binding that could be encountered in piston-cylinder arrangements. A core of a moving core transducer is mounted on each stylus. A moving core transducer consists of a primary coil and two oppositely wound secondary coils. The relative potential induced in each secondary is dependent upon the position of the core.

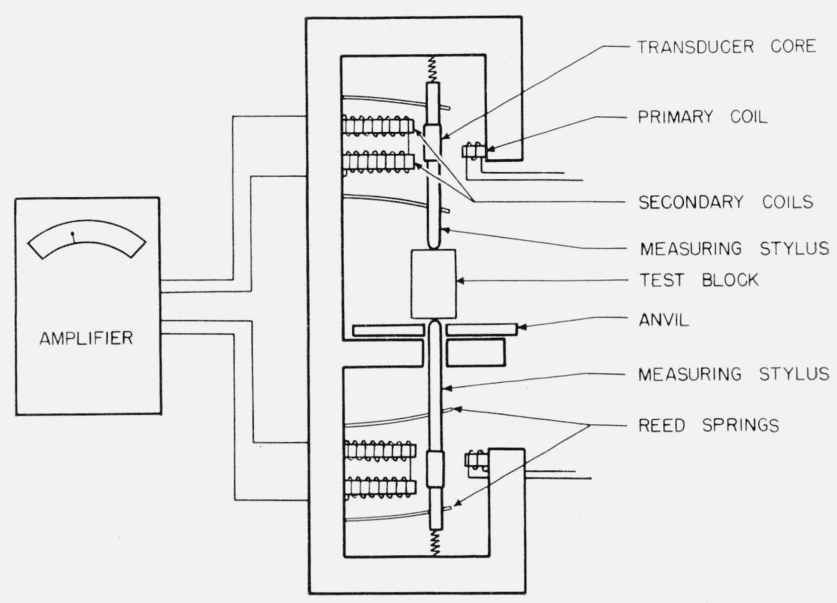

Figure 4. Elements of a mechanical comparator of lengths.

Thus, the position of the stylus is indicated. Amplification of the signal is provided so that deflection of the milliammeter needle magnifies movement of the stylus by approximately $2 \times 10^{5}$. In this instrument the top and bottom transducers provide opposing signals of equal magnitude so that effects of translation of the test piece in the direction of its critical length are cancelled in the combined signal. This reduces the need for extremely critical seating of the test piece on the anvil. Comparison of length is accomplished by noting the difference in readings of the calibrated scale as the test pieces are successively positioned between the measuring styluses. This type of comparison is referred to in this paper as a dynamic comparison because of the handling and transportation of the test piece just prior to the measurement, which in general, will cause growth or shrinkage due to change of thermal conditions. Attempts are usually made to control these thermal changes within practical limits.

In determining whether or not this type of length comparison would provide the precision necessary for the stability measurements, it was necessary to distinguish errors in comparison caused by lack of control of the dynamic effects from those due to the inherent randomness of the measuring instrument. The former could possibly be reduced to within acceptable limits, whereas the latter would establish the limit of precision that could be obtained with available instrumentation.

An indication of what might be expected in inherent randomness of the mechanical comparator was obtained in an acceptance test conducted when the 
instrument was purchased. This test measured the relationship between the meter reading and the pressure exerted by the measuring stylus, and avoided the effect from dynamic changes mentioned as it is independent of length. The results indicated that the inherent randomness of the instrument might possibly be limited to $0.5 \mu \mathrm{in}$. in comparisons of length. If this magnitude was a true indication of the instrument's potential performance in length comparisons, it was considered possible to achieve the desired precision provided thermal effects could be controlled to effectively eliminate or nullify the dynamic changes in length of the test specimens.

\subsection{Concepts Applied in the Measurement of Dynamic Length}

To effectively eliminate the dynamic changes, the comparison of test specimens would be required under temperature conditions that restricted temperature variation of the specimens to less than $0.02^{\circ} \mathrm{F}$. This seemed impractical. An approach to the problem was selected that attempts to nullify the dynamic changes in the comparison. It was reasoned that if test specimens to be compared could be treated identically during the comparison and if the specimens responded to thermal variation in an equal manner, dynamic changes of length could be nullified. Therefore the test specimens were divided into groups, all blocks in a group having similar thermal properties. One block of each group was selected as a secondary master. As the secondary masters would in genera! have different thermal characteristics than the primary master block, it was planned to compare the secondary masters with the primary master by using the interference comparator The secondary masters would then be used in dynamic comparisons with test specimens of their respective groups using the mechanical comparator.

Traditionally the secondary master would be compared with each test specimen in its group. This technique, however, gives special emphasis to the test specimen that was designated as a secondary master and thus violates the requirement of equal handling of all test specimens to nullify dynamic changes occurring during the comparisons. A more appropriate comparison system is one that has been used at NBS for the comparison of line standards of length with the national standard of length [18].
In this system, the master is handled as one of the test specimens of a group. All possible comparisons of specimens within the group are made to form one intercomparison test. If the group consists of $n$ specimens, $n(n-1)$ comparisons are made of $n(n-1) / 2$ pairs. For example table 5 indicates the comparisons to be made of a group containing four specimens, the secondary master $A$ and test specimens $B, C$, and $D$.

A possible method of reducing the data is to sum the columns and divide by the number of specimens in the group; e.g., $(\Sigma / 4) .^{5}$ This provides an average length of the specimen represented by the column relative to an average length of specimens within the group. The final results are obtained by forming all differences of column footings; i.e., the length of any specimen within the group relative to the length of any other specimen within the group is determined. Thus the lengths of $B, C$, and $D$ can be determined relative to the length of the secondary master $A$ and equal handling of all blocks of the group can be maintained. Each final result (difference in column footings) is then subtracted from the appropriate direct measurement; e.g., the column footing of $B$ minus the column footing of $A$ is subtracted from the actual measured comparison $B-A$. This provides a residual. A group of $n$ test specimens provides $n(n-1)$ residuals that may be used to evaluate the precision of the results of an intercomparison test which consists of $n(n-1)$ comparisons.

Conventionally, the sum of the squares of the residuals is determined and the probable error or the standard deviation computed. A multiple of this value is considered to represent a limit to be assigned to the test result. A prediction is made that a certain percentage of repeated tests of the same speci-

\footnotetext{
5 The usual statistical approach is to immediately reduce the measurement data by a least squares method which involves averaging the data obtained in the two measurements involving a given pair. Then the value appearing below the diagonal is the mirror image of the value of the reverse comparison appearing above the diagonal. This provides greater precision in the result as it eming above the diagonal. This provides greater precision in the result as it employs all measurement data involving a given specimen in evaluating its result.
However, this procedure can mask the presence of bias such as drift. In the However, this procedure can mask the presence of bias such as drift. In the
initial development of the measurement technique, precision of results was of secondary importance to the information concerning systematic errors that could be derived by analysis of the spread of the actual comparisons. By initially employing the method of data reduction shown in table 5 , the characteristics of the drift error were more apparent and a decision could be made as to whether particular measurement sequences, which are sometimes inconvenient, were required. In section 5.3. and appendix $\mathrm{D}$, an evolution from this simple program to the employment of least squares solution and the type of measurement sequence finally utilized is described.
}

TABLE 5. Comparisons performed in an intercomparison test on a group containing four specimens

\begin{tabular}{|c|c|c|c|c|}
\hline & $A$ & $B$ & $C$ & $D$ \\
\hline$A \ldots$ & $*$ & $B-A$ & $C-A$ & $D-A$ \\
\hline$B_{\ldots} \ldots$ & $A-B$ & $*$ & $C-B$ & $D-B$ \\
\hline$C_{\ldots-\ldots-}$ & $A-C$ & $B-C$ & $*$ & $D-C$ \\
\hline D $\ldots$ & $A-D$ & $B-D$ & $C-D$ & $*$ \\
\hline$\Sigma$ & $4 A-(A+B+C+D)$ & $4 B-(A+B+C+D)$ & $4 C-(A+B+C+D)$ & $4 D-(A+B+C+D)$ \\
\hline$\Sigma / 4 \ldots$ & $A-\frac{(A+B+C+D)}{4}$ & $B-\frac{(A+B+C+D)}{4}$ & $C-\frac{(A+B+C+D)}{4}$ & $D-\frac{(A+B+C+D)}{4}$ \\
\hline
\end{tabular}


mens, using the same measuring technique and equipment, will provide a similar test result within plus or minus this limit. For instance, it is usually accepted that three times the standard deviation will provide a limit within which 99.7 percent of the test results of a given specimen will be similar. This, in general, is a fallacy as such a condition depends upon the residuals being centered on zero and having a normal or Gaussian distribution.

Therefore, to obtain a better insight of the probable precision of the results of an intercomparison test and to possibly diagnose the type of measurement error occurring during an intercomparison test, it was decided to plot frequency distributions of the residuals, i.e., the magnitude of each residual plotted against the number of occurrences. It soon became evident that these distributions could serve as a powerful tool in the development of a satisfactory measuring technique. First, they allowed for a better estimate of the meaning of calculated probable error or standard deviation in regard to the precision of the results of an intercomparison test. Second, they indicated the success achieved in eliminating bias from the comparison procedures and indicated whether this success was temporary or was consistent in repeated intercomparison tests. Third, they served as a basis for hypothesizing the source of error and then served to indicate the effects of test refinements introduced in attempts to eliminate or nullify these sources.

The general procedure used in refining the comparison techniques was first to hypothesize from the residual distribution the nature of the systematic and random error. Then, when possible, the sequence of the comparisons was changed in an attempt to nullify the systematic error in the final results. When successful, a truer picture of the nature of the systematic error was obtained from the frequency distribution of the residuals. Attempts were then made to eliminate the systematic error from the comparisons until a random distribution of residuals was indicated. Even if systematic errors are nullified in the final results there is an advantage in eliminating the systematic errors from the individual comparisons. This can be accomplished by modification of the test procedure or fixtures in such a way as to eliminate the hypothesized systematic errors, or in some cases can be accomplished by variation in the treatment of the data; e.g., employing a least squares solution in the data reduction. When more random distributions are obtained as a result of such action, it not only verifies the hypothesis of the systematic error but provides frequency distributions of residuals that can more adequately indicate the origination of new systematic error in succeeding intercomparison tests. An example of this type of approach in the refinement of the testing technique is treated in appendix $\mathrm{D}$.

First, with ten specimens and then with eleven in an intercomparison group, the comparison sequences were changed and, where indicated by frequency distributions, modifications were made in handling of the test specimens and in the test fixtures. Section 5.3. contains some specific examples of such refinement and includes some examples of frequency distributions obtained during the development of the testing technique. Figure 5 indicates typical frequency distributions obtained during the initial (fig. $5 \mathrm{~A}$ ) and more advanced (fig. 5B) phases of the development of a satisfactory measuring method for the stability project.

\subsection{Statistical Control}

One of the important features in the development of the measurement method was the use of the results of statistical analyses of the data to guide the evolution of a measuring technique. The measuring technique and the least squares method of data reduction finally employed actually evolved from a series of modifications in procedure and equipment made on the basis of information obtained from the statistical analyses. This statistical approach was then further utilized as a control in monitoring the measuring technique to insure continuing uniformity.

A number of examples illustrate such utilization of these statistical analyses in the stability measurement program. The first of these involves a modification of the comparison schedule (order in which the 110 comparisons which make up an intercomparison test are performed) based on information obtained in the statistical analyses of the data. Utilizing the method of computation illustrated in table 5, the frequency distributions of the residuals in some of
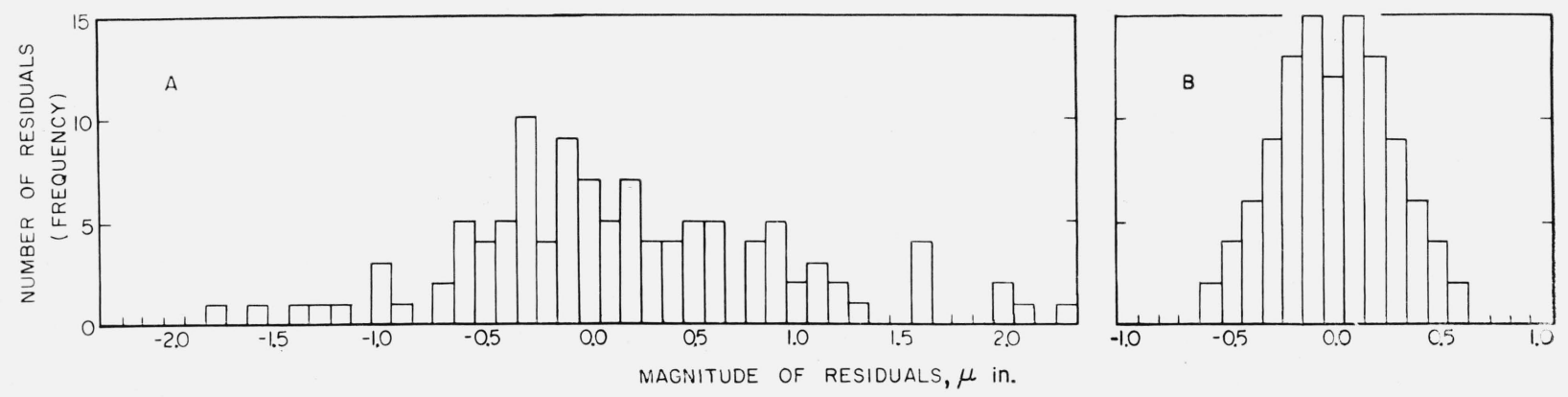

Figure 5. Example of frequency distributions of residuals obtained in two intercomparison tests.

A. Typical distribution obtained from an intercomparison test conducted during the initial development phase of the measuring technique. B. Typical distribution obtained from an intercomparison test conducted during a more ad vanced development phase of the measuring technique. 
of the early intercomparison tests in the program showed that the medians of these distributions were located at some point other than zero. This indicated a systematic error or drift which caused the system to quite consistently give either a larger or a smaller reading on each successive insertion of a sample into the comparator. ${ }^{6}$ An example of a distribution evidencing such a condition is shown in figure 6 where the median of the distribution is indicated by the arrow. This particular distribution obtained in one of the early intercomparison tests indicates a drift of three 10-millionths of an inch.

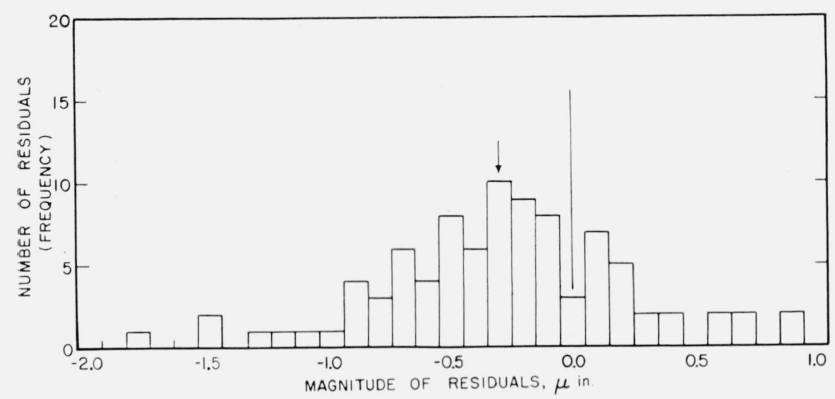

FiguRe 6. Frequency distribution of residuals obtained from an intercomparison test showing the presence of a drift effect.

Arrow indicates median of distribution.

To understand why the detection of this drift effect through statistical analysis of the data led to a change in the comparison schedule, it should be noted that there are two possible comparisons between any two sample blocks. Thus if the two blocks are block $A$ and block $B$, the two comparisons would be block $B$ against block $A$ and block $A$ against block $B$. The $B$ against $A$ comparison is made by placing block $A$ in the comparator, obtaining a scale reading, and then placing block $\mathrm{B}$ in the instrument and again noting the scale reading. Subtracting the reading on block $A$ from that on block $B$ gives the result of the first comparison, block $B$ minus block $A$. Similarly, the second comparison results in block $A$ minus block $B$. Now, however, if the drift effect causes the system to give a larger or smaller reading on each subsequent block, it is quite evident that the first comparison results not in block $B$ minus block $A$, but in block $B$ minus block $A$ plus a drift factor which is either positive or negative. Similarly, the second comparison gives block $A$ minus block $B$ plus a drift factor. The first effort to overcome this drift was an effort to insulate the final results of the intercomparison test from the drift effect. If the drift was constant in time, it would, in fact, be a constant error and would be nullified automatically and not affect the final results. (See footnote 13, appendix D.) Its effect on each measurement which would appear in the residuals could also be eliminated by employing a least squares solution in reducing the measurement data. This involves the following

${ }^{6}$ Employing the method of least squares solution in the reduction of the data would force the medians of the frequency distributions of residuals to zero and could reduce and possibly distort the indication of drift shown by the residuals. averaging procedure applied to the measurement data before the columns are summed. Consider again blocks $A$ and $B$ and let them have actual lengths $a$ and $b$ respectively. Let the drift effect contribute a variation in the length determinations of an amount $\alpha \Delta t$. Then the first comparison gives as a result $(b-a+\alpha \Delta t)$ and the second comparison gives $(a-b+\alpha \Delta t)$. Now if the result of the second comparison is subtracted from that of the first, and this quantity then divided by two, the drift effect is eliminated and for the first comparison the adjusted observed result, $(b-a)$, can be substituted. Similarly the negative of this, $(a-b)$, is obtained as an adjusted observed result for the second comparison.

On detection of this drift effect, such a least squares solution was quickly introduced into the data processing. However, at the time this drift was detected, the comparison schedule then employed called for a considerable lapse of time between the first and second comparisons on each pair of blocks. It was then thought quite possible that the drift would in general be a nonlinear function with respect to time, and in this case, of course, the least squares procedure would be ineffective in eliminating the influence of the drift effect upon the residuals. In addition it was believed that a more appropriate schedule of comparisons could be used to effectively eliminate such a nonlinear drift from the results of the intercomparison tests. For this reason, the comparison schedule was modified in such a way as to follow the form shown in appendix $\mathrm{D}$, table 10. This schedule was in turn modified to follow the form shown in appendix D, table 11 when it was recognized that successive comparisons of a pair of blocks could cause inhomogeneous comparison data. Thus the detection of the drift effect through statistical analysis led directly to a modification in the measurement program.

The statistical analyses of the data resulted in a number of other modifications of the measuring technique which are not here included, but an example of how a modification in the actual handling of the sample blocks resulted from information obtained in the statistical analyses might be illustrative. As was indicated above, the measurement of dynamic length depends to a very great extent on a symmetry of handling of the samples being measured. The symmetry of handling employed in the stability measurements evolved largely from consideration of the statistical controls. At an early stage in the development of the measuring technique here employed, it had been determined that in making the two comparisons between any pair of blocks it was necessary to physically handle the two blocks together as a pair rather than individually. Thus, in making the comparisons the two blocks involved in any two comparisons would be picked up together with the gloved hand and placed in the comparator. ${ }^{7}$

\footnotetext{
7 When it was realized that blocks were to be handled in pairs, it was decided to employ, if possible, the operator's hand as a tool to convey the blocks through the comparison procedures. Other tools, such as tongs, introduced too great possibility that mechanical shock, because of accidental dropping, would be introduced as an uncontrolled factor affecting stability. To minimize thermal effect, cotton flannel gloves were used.
} 
The first and then the second comparison would be made and the blocks then returned as a pair to the storage area. Such a handling procedure, it was believed at the time, resulted in the two blocks in any comparison receiving equal, symmetrical handling. Examination of the residual frequency distributions obtained at this time, however, indicated that the manner in which the blocks were held in the gloved hand had a significant effect on the residuals of the intercomparison tests. At the time this effect was noticed, the blocks were being held as illustrated in the upper portion of figure 7 with one block of the pair exposed to the palm of the glove insulated hand. The residual distribution obtained in an intercomparison test in which this handling technique was employed is shown in figure 8. It should be noted that the total distribution is plotted at the bottom of the figure, and this distribution is then broken
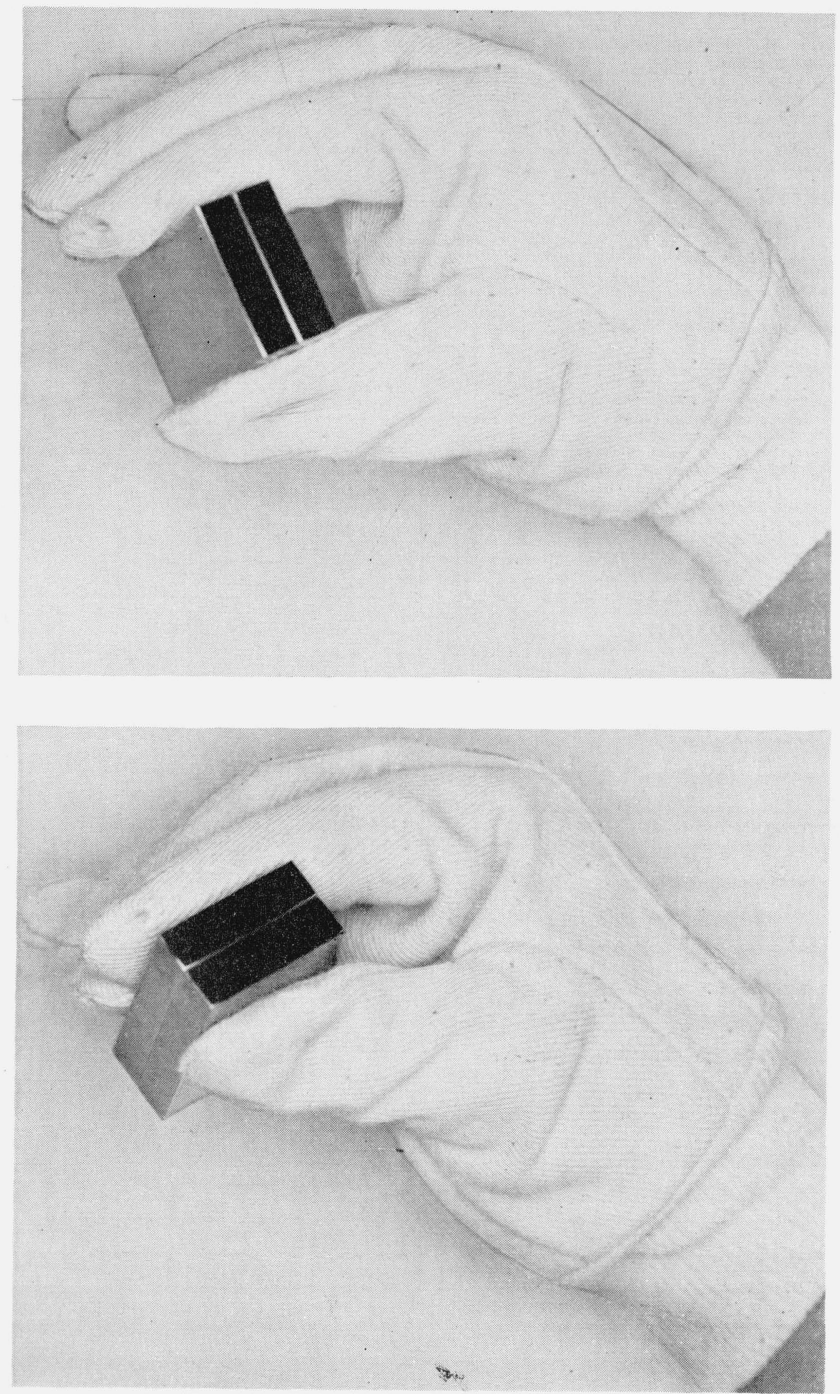

FIgURE 7. Manner of handling two gage blocks for comparison measurement.

Top-Handling that produced asymmetrical thermal effect.

Bottom-Modification employed to correct asymmetrical condition.
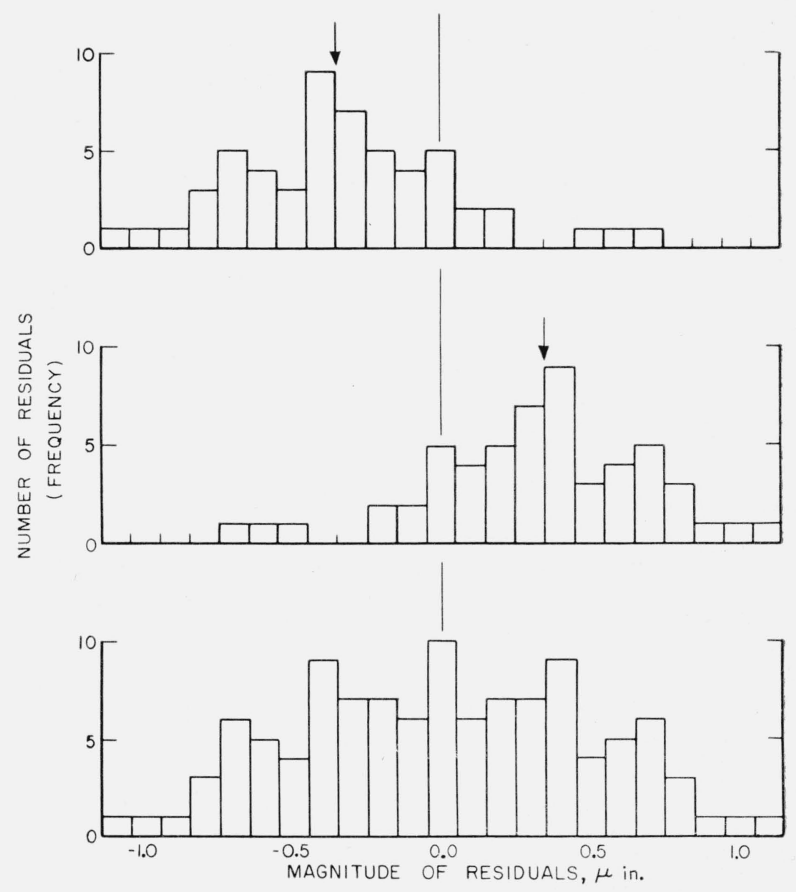

FIGURE 8. Frequency distribution of residuals obtained in an intercomparison test.

Handling introduced asymmetrical thermal effects as shown by separation of median

Top-Distribution obtained from second comparisons of pairs of gage blocks. Center-Distribution obtained from first comparisons of pairs of gage blocks. Bottom-Total distribution of residuals.

down into the two distributions shown in the upper portion of the figure. The distribution of residuals resulting from first comparisons between each pair of blocks is shown in the central plot, while that obtained from second comparisons is plotted at the top of the figure. It can be seen that the medians of the first and second comparison distributions, shown by the arrows, are not alined, but are separated by seven 10 -millionths of an inch.

The asymmetry suspected as the cause of the split between the medians of the first and second comparison distributions shown in figure 8 was in the handling of the blocks; one block was exposed to the palm of the gloved hand while the other block was not so exposed. This can be seen in the illustration of the handling technique at that time employed, as shown in the upper portion of figure 7 . This suspicion led to changing the manner in which the blocks were held to that shown in the lower view of figure 7 . When this handling technique was employed the residual distribution shown in figure 9 was obtained. Here, the medians of the first and second comparison distributions are separated by only one 10 -millionth of an inch indicating that the asvmmetry has been sharply reduced. This shows how the use of the statistical controls led to a modification of the actual handling techniques employed.

One further example of the application of statistical control to the intercomparison tests will illustrate how statistical analyses can be effectively used to monitor the measuring technique and detect break- 


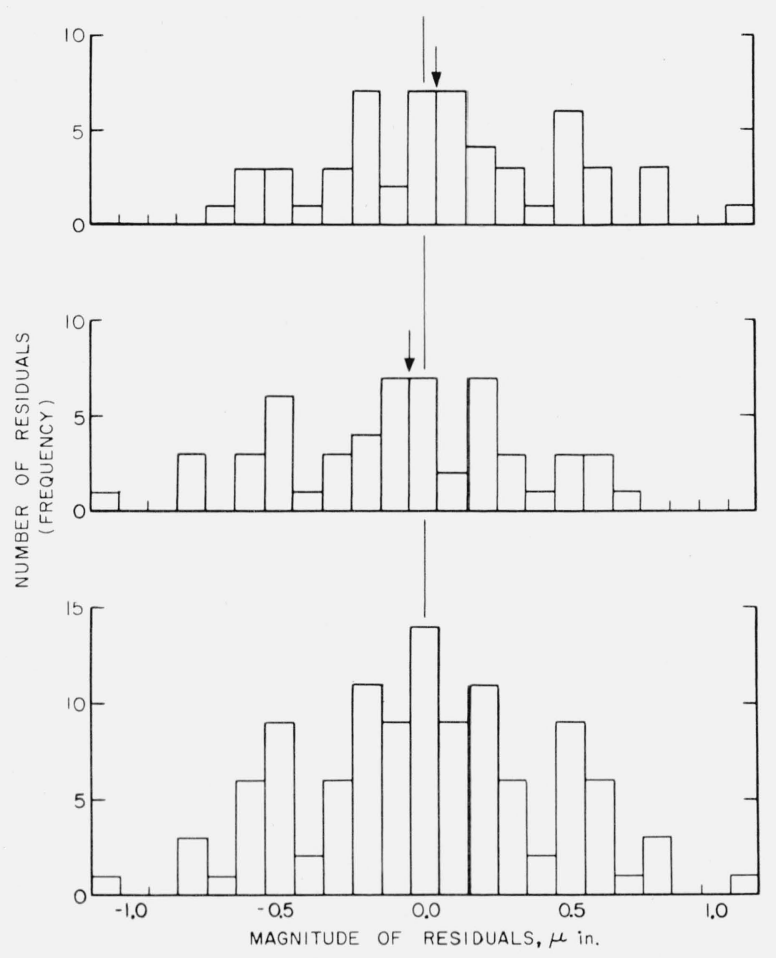

FIGURE 9. Frequency distribution obtained from an intercomparison test when handling was modified to correct asymmetrical condition.

Close alinement of the medians shows absence of asymmetrical condition. Top-Distribution obtained from second comparisons of pairs of gage blocks. Center-Distribution obtained from first comparisons of pairs of gage blocks. Botton-Total distribution of residuals.

downs in the technique which might not otherwise be evident.

After a series of modifications in technique finally resulted in the development of a satisfactory intercomparison procedure, this procedure was employed on all the intercomparison tests and regularly gave residual distributions comparable to that shown in figure 9. Then, after a considerable number of intercomparison tests had been run using this procedure, the residual distribution shown in figure 10 was obtained. This again indicates, by the split between the medians of the first and second comparison distributions, that an asymmetry was present during this particular intercomparison test. A similar asymmetry was evidenced in the residual distributions of succeeding intercomparison tests indicating that some breakdown in the system had occurred. Careful examination revealed that actually there had been an asymmetry in the comparison procedure all along but that its effects had been eliminated from the earlier intercomparison tests by other precautions, and that these precautions had now broken down causing the asymmetry to be revealed. As indicated above, the gage blocks during comparison were always handled in pairs and gloves were employed for this handling to insulate the blocks, to a certain extent, from the hand. To get the two blocks of a pair together, since the blocks were

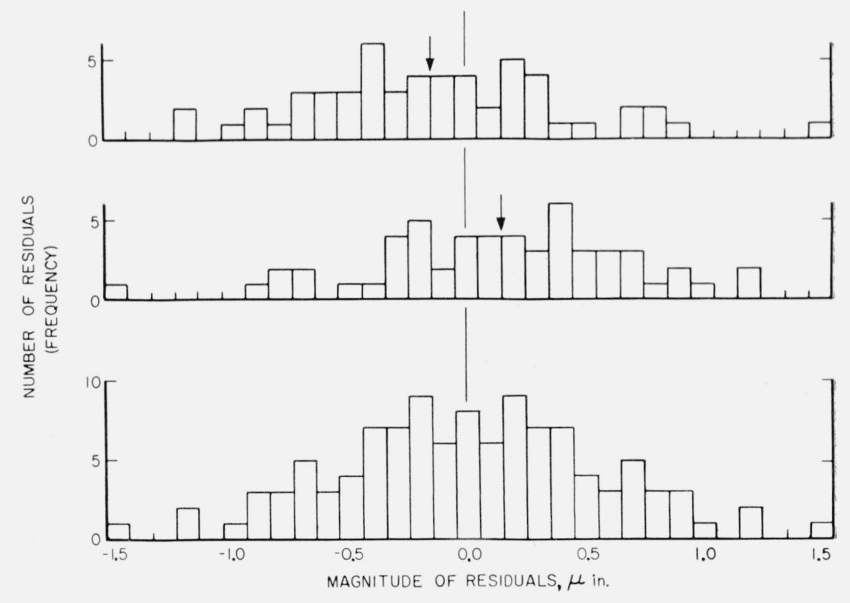

Figure 10. Frequency distribution of residuals obtained in an intercomparison test when a breakdown of test fixtures activated a dormant asymmetry in technique.

Separation of distribution medians shows the presence of an asymmetrical condition.

Top-Distribution obtained from second comparisons of pairs of gage blocks. Center-Distribution obtained from first comparisons of pairs of gage blocks. Bottom-Total distribution of residuals.

spread out on a storage area, it was necessary to pick up first one block and then the other. Thus, the first block picked up was given more time to be affected by the handling before its measurement than was the second block and this is an asymmetrical condition. The gloves had been used from the start to minimize the effects of handling, but at the time this asymmetry was detected, it was noticed that the gloves employed had become worn and impregnated with foreign material. It was suspected that in this condition the effectiveness of the gloves in shielding the comparisons from the asymmetry involved in picking up the blocks one at a time was reduced.

To determine whether this was indeed the case, the handling technique was modified in the following wav. In previous tests, the gage blocks had been picked up one at a time from the storage area and placed on a loading stage so that the pair could then be picked up together for the comparisons. This procedure was modified by using a pair of tongs to pick up the blocks one at a time from the storage area and place them on the loading stage. The tongs were then put aside and the pair of blocks were picked up together from the loading stage as before, with the gloved hand. The comparisons were then made just as before.

This modification of the handling technique removed the gloved hand from the asymmetrical initial portion of the handling procedure and hence if the sudden appearance of the asymmetrical condition was due to the failure of the gloves, the asymmetry should have been eliminated with this modification. That this occurred is illustrated by figure 11 which shows the residual distribution obtained when the tongs replaced the gloved hand in the initial asymmetrical portion of the handling procedure. This modified technique was then 


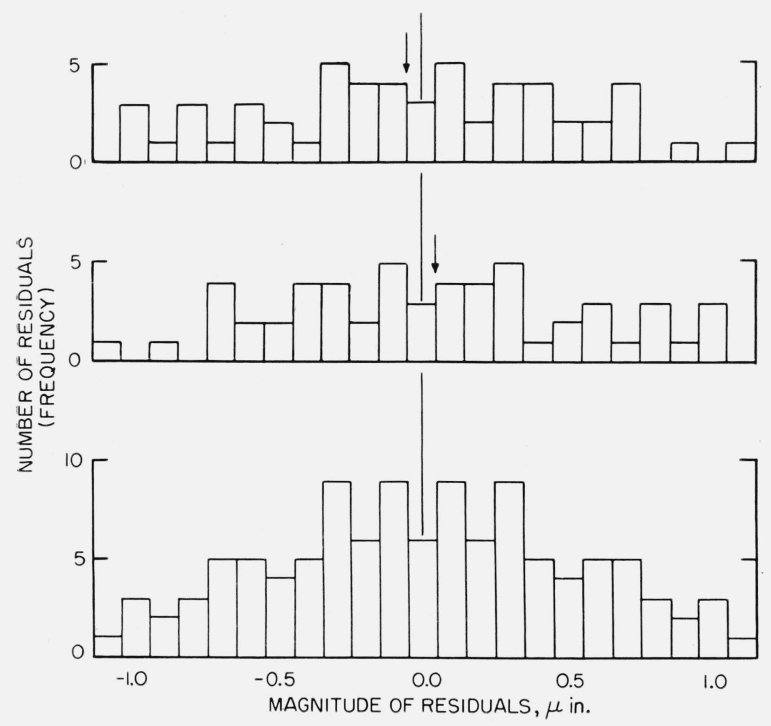

FIGURE 11. Frequency distribution of residuals obtained in an intercomparison test when modification in test fixtures was introduced to correct an asymmetrical condition.

Close alinement of the medians shows absence of asymmetrical condition. Top-Distribution obtained from second comparisons of pairs of gage blocks. Center-Distribution obtained from first comparisons of pairs of gage blocks. Bottom-Total distribution of residuals.

adopted for all subsequent intercomparison tests, but this example illustrates how statistical control was employed to detect a breakdown in the technique and indicates the value of continuing to employ such control as a monitor of the measurement method.

This type of statistical control is, however, ineffective as a monitor in detecting certain types of nonuniformity in the measuring method. In particular, it will not detect variation in measurement technique which results in a change in the relationships between lengths of the blocks of an intercomparison group when these changed relationships continue throughout the time interval of one complete intercomparison test. An example of this type of variation in procedure occurred during the testing of one intercomparison group of gage blocks. Intercomparison tests had been run on this particular group for a period of several months. The regularly employed procedure was used in each intercomparison test, but on the date of one test an interferometric measurement of one block in the group was planned for the same date on which an intercomparison test was to be run. The normal procedure for an intercomparison test called for the eleven blocks in the group to be placed on the storage area of the intercomparison test equipment the night before the intercomparison test was to be run and left there overnight until the test was begun in the morning. The normal procedure for the interferometric measurement called for the placing of the block to be measured in the interferometer the night before the measurement was to be made. However, since the interferometric measurement of the one block in this set would only take a few minutes in the morning before the intercomparison test, it was decided to proceed with the interferometric measurement and the intercomparison test both on the same day. Thus the block to be measured interferometrically, the F302 block, was placed in the interferometer the night before the date of the two tests and left there overnight, while the other 10 blocks in the group were placed on the storage area of the intercomparison test equipment and left there overnight just as the normal procedure required. In the morning, the F302 block was measured interferometrically and was taken from the interferometer and placed on the storage area with the other 10 blocks, a horizontal movement of approximately $6 \mathrm{ft}$ within the constant temperature room. An hour later the intercomparison test was begun following the normal procedure and this test took perhaps $4 \mathrm{hr}$. Calculation of the data and plotting of the residual distribution gave the distribution shown in figure 12, which shows an excellent distribution. However, when the relationships between the F302 block and the other blocks in the group were examined, the results of this intercomparison test appeared anomalous. This is illustrated in figure 13, where the differences in length are plotted for the following blocks: F323 minus F302, F327 minus F302, and F330 minus F302. These data were determined in successive intercomparison tests on the group containing these blocks. The plotted points

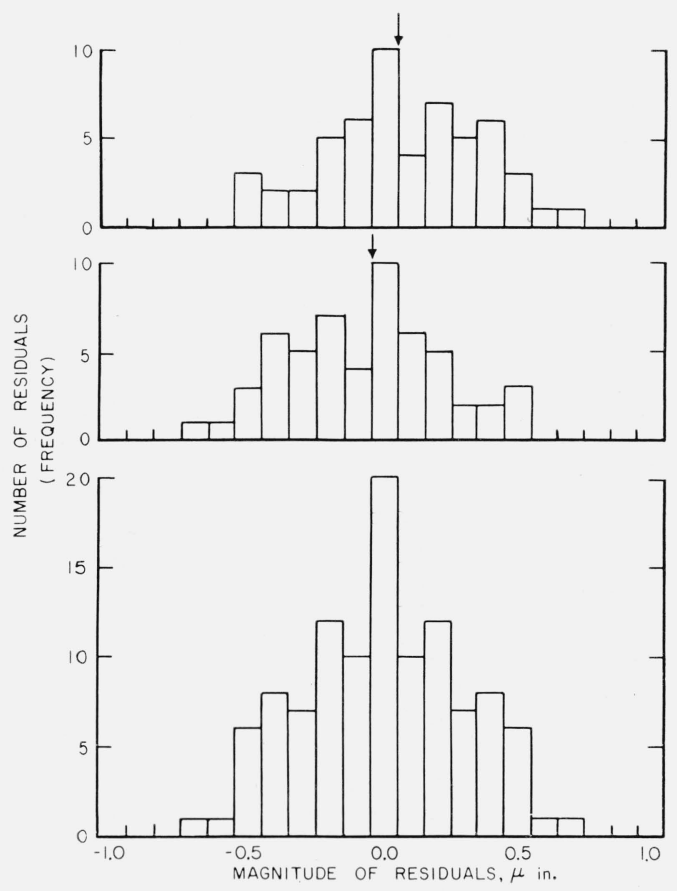

FiguRE 12. Frequency distribution of residuals obtained in an intercomparison test which produced anomalous results.

Notice that the distributions do not indicate the effect which produced the anomaly

Top-Distribution obtained from second comparisons of pairs of gage blocks.

Center-Distribution obtained from first comparisons of pairs of gage blocks. Bottom-Total distribution of residuals. 


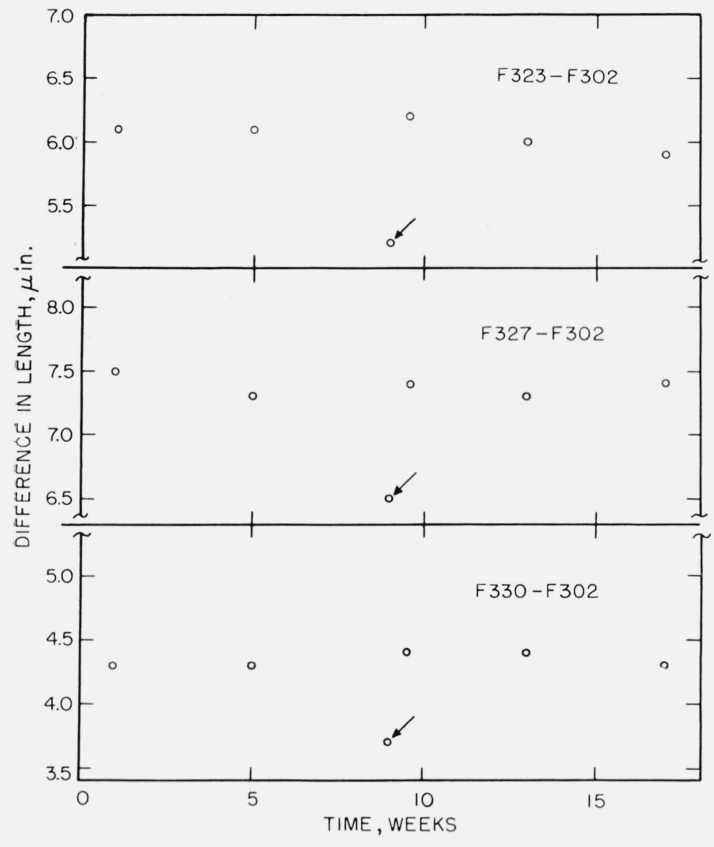

Figure 13. Illustration of anomalous results obtained in one intercomparison test in which the F302 gage block received a different handling prior to the tesi.

indicate the values obtained for these differences in each particular intercomparison test. The values obtained in the test here in question are marked on each graph by the small arrows. It can be seen that the values obtained in the intercomparison tests preceding this one show a certain consistency. The test in question, however, in each case gave a value several ten-millionths of an inch lower than the previously consistent values. Yet the only variation in testing procedure noticed was the different treatment afforded the F302 block prior to the intercomparison test, occasioned by the procedure involved in its interferometric measurement. To determine whether this variation was indeed the significant factor, another intercomparison test was run on this same group of blocks four days later, with care being taken that the normal procedure was followed throughout the handling and the test. The values obtained in this and subsequent intercomparison tests are shown in figure 13 to the right of those marked with the small arrows. These values are again consistent with those obtained prior to the intercomparison test in which the variation occurred. Thus it appears that the anomalous results are indeed due to the variation in procedure which caused the F302 block to receive different treatment from that received by the other ten blocks in the group. Further, it should be noted that this variation went undetected by the residual distributions employed as statistical controls (figure 12). This indicates that while these controls are of considerable value in maintaining uniformity of technique, they are, nevertheless, ineffective with certain types of variation.

\section{Results of Stability Measurements}

\subsection{Method of Presenting Data}

The data obtained from the observation of stability are presented in figures $14,15,16$, and 17 . In these figures, time elapsed since final heat treatment is plotted against change in length. Each plotted point has an upper and lower limit which is the estimated precision of the determination. This estimate was based upon the statistical information derived from the test itself. When the frequency distribution of all the measurement residuals of an intercomparison test indicated a near normal distribution and when the residuals were limited to a range within 3 times the calculated standard deviation of a single reading, the evaluated precision of the intercomparison test was estimated to be 3 times the computed standard deviation of the final result. When the range of the frequency distribution exceeded that to be expected from the calculated standard deviation, a factor of 4 times the standard deviation was applied as an estimate of precision.

Large backloads at the grinding shop and time spent accumulating sufficient blocks for an efficient lap load, in some cases, caused considerable delay in the interval between final heat treatment (stress relief) and final lapping. In addition, procedures for measuring the blocks were being developed simultaneously and were not ready until after some of the blocks had been completed for some time. Plotting the time elapsed since final heat treatment compensated for the delays and put each block on a more comparable basis.

\subsection{Commercial Gage Blocks}

As a basis of comparison, a total of seven 2 in. steel gage blocks, two from each of three manufacturers and one ${ }^{8}$ from a fourth, were purchased on the open market and incorporated into the measuring program. The blocks were ordered as "AA" grade, the best quality available. The results obtained from observing the stability of these blocks are shown in figure 14. The abscissa for this figure is the number of months elapsed since purchase. While it would have been more desirable to have plotted the months elapsed since final heat treatment, such data were not available. All of the commercial blocks have become shorter, although block $A$ of manufacturer 2 and blocks $A$ and $B$ of manufacturer 3 initially indicated a tendency towards growth. There is also a considerable degree of similarity between the stability characteristics of paired blocks from each manufacturer. The apparent overall stability of these blocks, extrapolated to a period of one year, ranges from a minimum of $-0.7 \times 10^{-6} \mathrm{in} . /$ in. to a maximum of $-1.9 \times 10^{-6} \mathrm{in}$./in. The average change in length for the seven blocks is $-1.1 \times 10^{-6}$ in./in./yr, which is adequate to maintain size within the current Federal specification for only $2 \mathrm{yr}$. It is

\footnotetext{
$\$$ Two blocks were purchased, but one was unsuitable for measurement.
} 


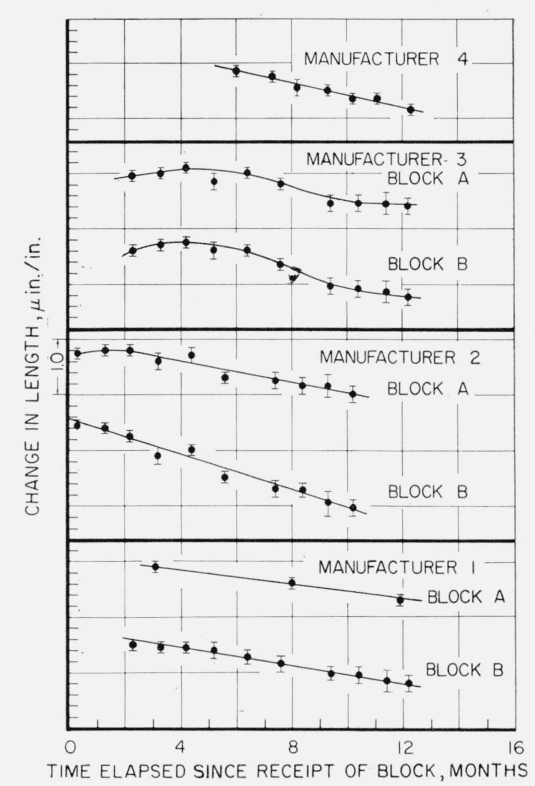

FIGURE 14. The stability of commercial gage blocks of " $A A$ " grade obtained directly from four manufacturess.

a standard procedure of some manufacturers to finish their blocks on the positive side of the tolerance to allow for what is claimed to be wear. This procedure could extend the time within tolerance for the average of these blocks to $4 \mathrm{yr}$, assuming a uniform continuance of the contraction.

\subsection{0, Hardened}

The results of stability measurements on hardened 52100 steel gage blocks are shown in figure 15 , and include blocks hardened either by martempering or by direct quenching. The six curves plotted in section A represent stability characteristics of blocks given the lowest final temper and stress relief so as to obtain a hardness of $65 \mathrm{R}_{\mathrm{c}}$. Each block that was measured during the first 5 months became shorter, and became nearly stable for the remaining period of observation; block T-337 showed a slight tendency to decrease in length with increase in time over the entire period of its observation. The initial contraction was more pronounced in those blocks measured soon after final stress relief, and very small or absent in blocks whose initial measurements were made 5 months after heat treatment. All six curves have similar characteristics, regardless of whether the blocks they represent were martempered or quenched. The overall change in length computed on the basis of one year ranges from $-0.2 \times 10^{-6}$ to $-0.7 \times 10^{-6} \mathrm{in}$./in. The average change for the six blocks is $-0.4 \times 10^{-6}$ in./in., a value indicating approximately three times more stability than the commercial blocks. A more realistic approach is to compute the length changes after the sixth month, since the blocks appear essentially stable once the initial rate of contraction has subsided. On this basis the minimum change, extrapolated to $1 \mathrm{yr}$, is 0.0 and the maximum $-0.3 \times 10^{-6} \mathrm{in} . / \mathrm{in} . / \mathrm{yr}$. The average is a very low $-0.1 \times 10^{-6} \mathrm{in} . / \mathrm{in} . / \mathrm{yr}$, indicating about 10 times greater stability than the commercial average, and well within the goals of \pm 0.2 $\times 10^{-6} \mathrm{in}$./in./yr set for this investigation.

The four curves in section B and the four in section $\mathrm{C}$ of figure 15 represent the stability of blocks that were given final tempers and stress relief treatments at temperatures in excess of $250^{\circ} \mathrm{F}$ to reduce nominal hardness to $62 \mathrm{R}_{\mathrm{c}}$, and $60 \mathrm{R}_{\mathrm{c}}$ respectively. These stability results were not anticipated, for it was initially reasoned that the higher tempering and stress relief temperatures would produce a more stable structure and stress pattern. Instead, the eight blocks represented by the curves in B and $\mathrm{C}$ appear less stable than those in $\mathrm{A}$. The directly quenched blocks in $\mathrm{B}$ and $\mathrm{C}(\mathrm{T}-377, \mathrm{~T}-378, \mathrm{~T}-384$, T-386) have not been observed sufficiently long to ascertain the exact shape of their stability curves. Although the curves for the four blocks have been drawn linearly, they all exhibit what could be a tendency to flatten during the last four measurements. Nevertheless, the shapes of the curves are undoubtedly different from the curves of the matching martempered blocks in sections $\mathrm{B}$ and $\mathrm{C}(\mathrm{T}-351$, $\mathrm{T}-356, \mathrm{~T}-357, \mathrm{~T}-359)$. The four directly quenched blocks were the only blocks whose nongaging surfaces were ground perpendicular to the 2 in. dimension; all others were ground parallel.

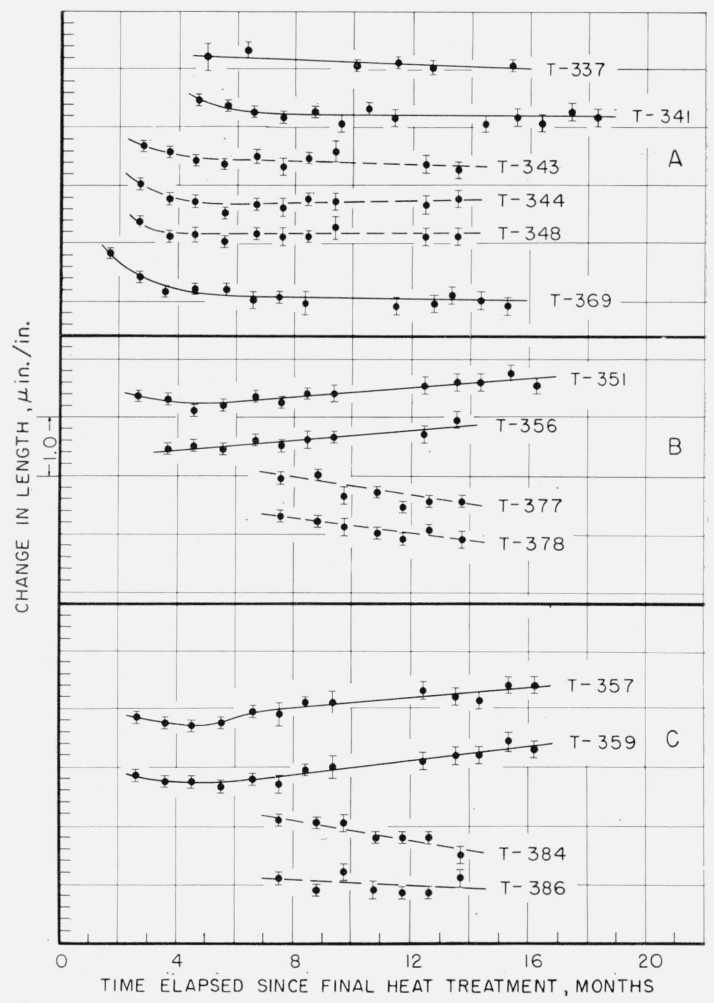

Figure 15. The stability of hardened and stabilized 52100 experimental gage blocks.

Solid lines represent martempered blocks, dashed lines represent directly quenched blocks.

A, $65 \mathrm{R}_{\mathrm{c}}$; B, $62 \mathrm{R}_{\mathrm{c}}$; C, $60 \mathrm{R}_{\mathrm{c}}$. 
The large surfaces adjacent to the gaging surfaces of two hardened 52100 gage blocks were analyzed for residual stresses by W. E. Littman and A. L. Christenson, The Timken Roller Bearing Co., in accordance with the X-ray techniques of Christenson and Rowland [19]. One of these blocks had been heat treated for maximum hardness $\left(65 \mathrm{R}_{\mathrm{c}}\right)$ and ground in a manner identical to blocks $\mathrm{T}-343, \mathrm{~T}-344$, and $\mathrm{T}-348$ (section A, fig. 15). The other was prepared with a hardness of $60 \mathrm{R}_{\mathrm{c}}$ in a manner identical to that used for blocks T-384 and T-386. The block tempered at $250^{\circ} \mathrm{F}$ to a hardness of $65 \mathrm{R}_{\mathrm{c}}$ had a residual compressive surface stress of 14,400 psi parallel to the grinding direction and 60,200 psi perpendicular to the grinding direction. The block tempered at $465^{\circ}$ $\mathrm{F}\left(60 \mathrm{R}_{\mathrm{c}}\right)$ had residual compressive stresses of 20,100 psi parallel and 70,500 psi perpendicular to the grinding direction. Thus, the data indicate that the compressive stresses in the surfaces of the blocks actually increase with an increase in the tempering temperature from $250^{\circ}$ to $465^{\circ} \mathrm{F}$. Therefore, it is postulated that the process of tempering at temperatures in excess of $250^{\circ} \mathrm{F}$ caused a structural change within the block which was accompanied by a contraction. The surface stresses, however, were not relieved at a rate sufficiently high to counterbalance the internal contractions, with the overall result that the compressive stresses in the surface were increased by the increase in tempering temperature. The net result seems to have been an unbalance between the subsequent structural and lattice changes and the distribution and size of residual stresses, which in turn has contributed to a growth of four blocks ( $\mathrm{T}-351, \mathrm{~T}-356, \mathrm{~T}-357, \mathrm{~T}-359)$ in sections $\mathrm{B}$ and $\mathrm{C}$, figure 15. On the other hand, grinding the other four blocks at a 90 degrees direction has shifted the maximum observed compressive stress by 90 degrees. It is suggested that the observed shrinkage in these blocks is caused by the change in the orientation of the stress patterns. These comments concerning the influence of grinding stresses are considered tentative and several experiments have been designed and are in progress which are expected to lead to a clarification of the problem.

\subsection{Stainless, Annealed and Nitrided}

The results of stability measurements on annealed and nitrided 410 stainless gage blocks are shown in figure 16. The four curves plotted in section A represent the stability characteristics of blocks nitrided by the two stage process and whose nongaging surfaces were not ground or otherwise machined after nitriding. The entire group (A) exhibits similar stability characteristies; the slope of each curve is almost the same. There was practically no deviation from linearity during the entire 13 month period of observation, although a tendency towards additional flattening may be indicated in the last four measurements. It is unfortunate that no measurements could be made prior to the twelfth month after heat treatment, so that the behavior of these blocks during the first year could have been observed. The

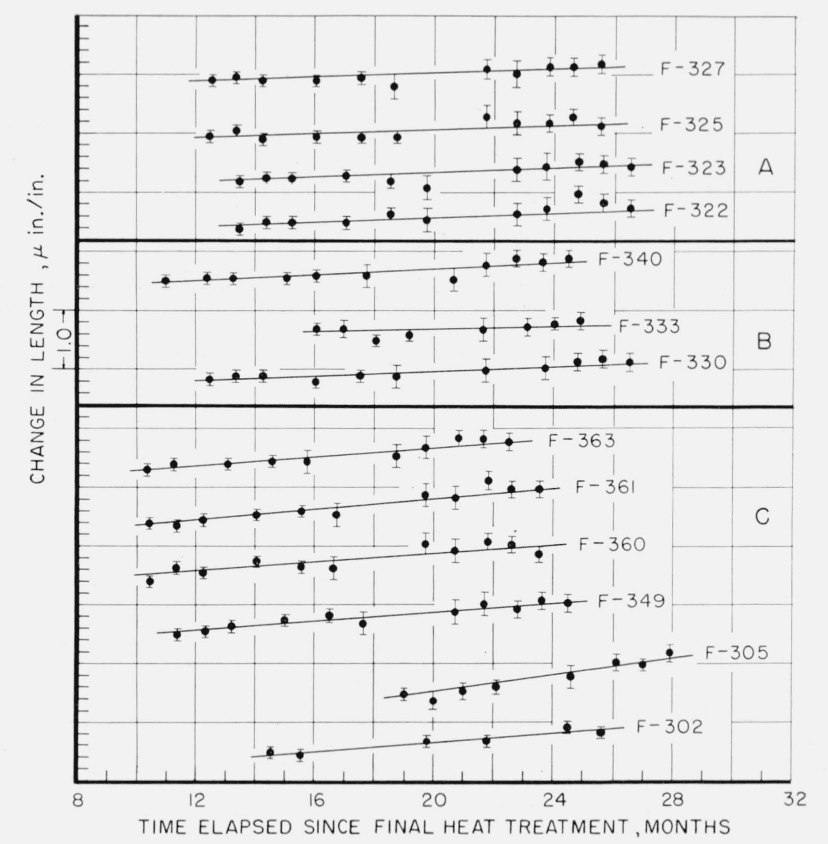

FIgURE 16. The stability of nitrided, initially annealed 410 stainless steel gage blocks.

A. Nitrided by two stage process, nongaging surfaces left as nitrided. $\mathrm{B}$. Nitrided by single stage process, white layer removed from nongaging surfaces.

C. Nitrided by single stage process, nitrided case complesely removed from nongaging surfaces.

overall change in length computed on the basis of 1 year is a consistent $+0.2 \times 10^{-6} \mathrm{in}$./in./yr. This value just meets the degree of tolerance sought in this investigation. Based on a 1 year interval, any one of these blocks is about 3 times more stable than the best of the commercial blocks tested, 5 times more stable than the average, and 9 times more stable than the least stable.

The curves in section B of figure 16 represent data from three blocks which were nitrided by the conventional single stage process. The preparation of these blocks also differs from that in section $\mathrm{A}$ in that the white layer on the nongaging surfaces was ground off, so as to leave a hard, bright, nitrided case. The stability of these blocks is almost the same as for those in section $\mathrm{A}$. The range is $+0.1 \times 10^{-6}$ to $+0.3 \times 10^{-6}$ in. /in./yr with an a verage of $+0.2 \times 10^{-6}$. The curve for $\mathrm{F}-333$ has an extremely low slope, but this block has been observed for only 9 months and the trend of the last four points is towards greater slope. The average of this group is equivalent to that of group A, but there is slightly more scatter.

The blocks represented by the curves in section $\mathrm{C}$ of figure 16 were nitrided by the single stage process and differ from those in $B$ in that all of the nitrided cases were removed from the four nongaging faces by grinding. These blocks exhibit the same trend towards uniform linear growth, but the rate is higher. The range is $+0.4 \times 10^{-6}$ to $+0.9 \times 10^{-6} \mathrm{in}$. $/ \mathrm{in}$. $/ \mathrm{yr}$ with an average of $+0.6 \times 10^{-6}$. Except for block F-305 each curve has a similar slope, and again the nonconforming curve was drawn through fewer points of observations. The last two or three points 
plotted for each curve, except F-305, indicate a downtrend. The average of this group is more stable than the most stable commercial block observed, and has twice the degree of stability as the average of the commercial group.

If the assumption is made that the 410 stainless, as annealed, has a normal tendency to grow, and the data support this assumption, then the improved performance of the blocks with nitrided nongaging faces could be explained. The nitrided surfaces could serve as a restraining jacket, which would be more effective with increasing thickness. Thus, the blocks whose nongaging faces were not ground at all (A, fig. 16) had the thickest case and grew the least, those whose white layer was removed (B, fig. 16) had a thinner case and indicated slightly less uniform stability characteristics, and those whose case was removed entirely (C, fig. 16 ) had maximum growth. The investigation is being extended to further evaluate the effect of the thickness of nitrided cases on nongaging faces.

Residual stress determinations were made by Littman and Christenson on the nongaging surfaces of nitrided 410 stainless steel blocks. A block processed similarly to those in section A of figure 16 had residual tensile stresses of 3,000 psi parallel to the 2 in. gaging length and 2,800 psi perpendicular to the gaging length (these blocks not ground after nitriding). A block processed like those in section $B$ had a residual tensile stress of 31,100 psi in the direction parallel to grinding (stresses perpendicular to grinding not determined), while a block representative of those in $\mathrm{C}$ had compressive stresses of 1,300 psi parallel to grinding and only 900 psi perpendicular to grinding. Except for the fact that the relief of residual compressive stresses would be expected to cause growth, no apparent relationship can be seen between the reported residual stresses and the rate of growth of the different blocks. In actuality, the values of residual stress reported for blocks in $\mathrm{A}$ and in $\mathrm{C}$ are very low and should not have contributed materially to length changes.

As with the hardened 52100 blocks, several additional experimental treatments have been designed which should contribute additionally to the understanding of the role of surface stresses.

\subsection{Blocks With Hard Coatings}

The results of stability measurements on both annealed 52100 and annealed 410 gage blocks with hard coatings are given in figure 17. The stability characteristics of 52100 steel coated only on the gaging surfaces with thermal sprayed nickel-chromium-boron alloy is represented in section $A$. The steel was heated after coating to fuse the particles and some degree of hardening occurred as a result. The hardness of the steel after the fusion treatment was $43 \mathrm{R}_{\mathrm{c}}$. Both blocks have similar characteristics, both grew slowly at a linear rate. T-309 grew

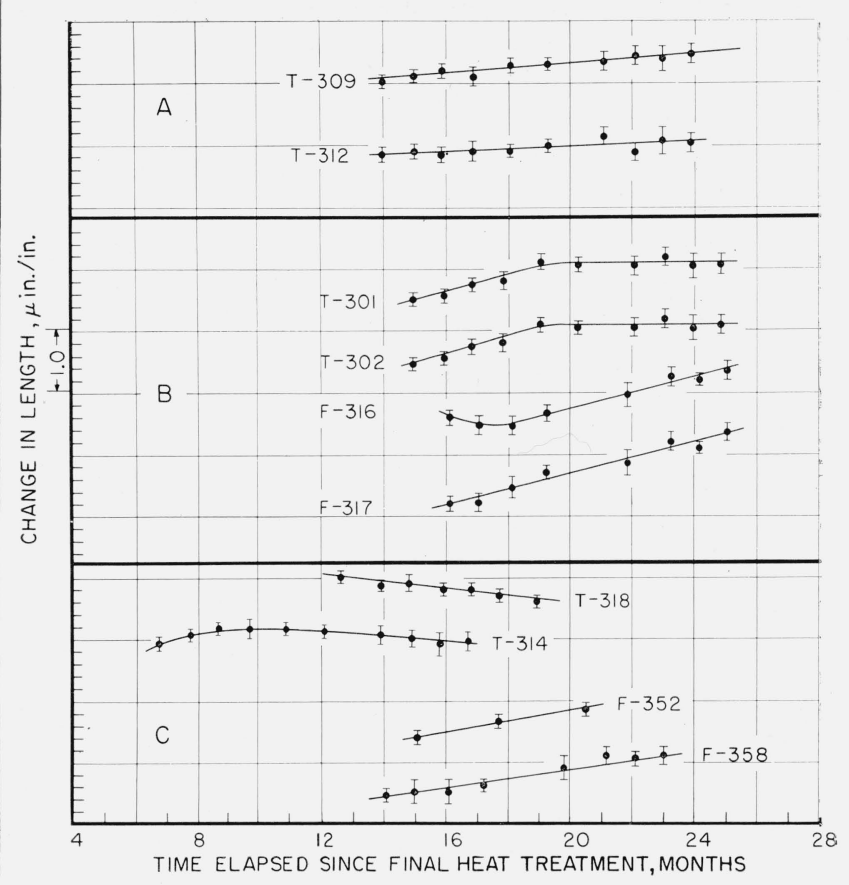

Figure 17. The stability of initially annealed $52100 \quad(T$ blocks) and 410 stainless steel gage blocks ( $F$ blocks) with hard coatings.

A. Gaging surfaces coated with thermal sprayed nickel-chromium-boron alloy B. Gaging surfaces coated with flame plated tungsten carbide.

C. Surfaces electroplated with chromium, T blocks on all surfaces, $\mathrm{F}$ blocks on gaging surfaces only.

$0.5 \times 10^{-6}$ in./in., extrapolated to $1 \mathrm{yr}$, and $\mathrm{T}-312$ grew $0.3 \times 10^{-6} \mathrm{in}$./in./yr.

The blocks represented in section B, figure 17 , have been flame plated with tungsten carbide on gaging surfaces only. Both of the 52100 blocks (T-301 and T-302) have similar stability characteristics. Initially they expanded at a rate similar to 410 stainless block $\mathrm{F}-317$ in section $\mathrm{B}$, but they have exhibited more stable characteristics during the last 6 months of observation. The 410 blocks have grown rapidly, much more so than the nitrided blocks in section $\mathrm{C}$ of figure 16 . This particular comparison is made because the blocks in figure $16 \mathrm{C}$ were ground on the nongaging faces and stress relieved at $975^{\circ} \mathrm{F}$ in the same manner as the blocks illustrated in section $\mathrm{B}$ of figure 17. Therefore, the core material in each group has essentially the same structure and residual surface stress pattern and the difference in behavior can be attributed to the cases.

The blocks whose stability characteristics are shown in section C figure 17 were chromium electroplated. T-314 and T-318 were plated on all six surfaces and the plating on the nongaging faces was ground sufficiently to obtain desired dimensions. Blocks $\mathrm{F}-352$ and $\mathrm{F}-358$ were plated on the ends only. The 52100 blocks are reacting similarly to one another and the two 410 stainless blocks also have curves similar to each other. The former are contracting although there was an initial increase in T-314. The chromium plated 410 stainless blocks are increasing in size at a fairly rapid rate. 


\subsection{Overall Observations}

\section{a. On Stability of Gage Blocks}

The comparative changes in length for all of the blocks, arranged in order of increasing change, are summarized in table 6. A time increment of $1 \mathrm{yr}$ has been used, which necessitated extrapolation in some cases. The most stable groups of blocks for the period observed were the nitrided 410 stainless with all or portions of the nitrided cases left on all surfaces. These blocks had stability characteristics that met the goal set for this investigation, namely, a maximum dimensional change of $2 \times 10^{-7} \mathrm{in}$./in./yr. These blocks proved to be resistant to normal atmospheric corrosion and accepted the best lapped finish of any block tested. The reproducibility of performance in these blocks, as evidenced by the uniformity of slope and low spread of individual values in each group, was also excellent. There was no apparent deviation from linearity in the dimensional changes of any of the nitrided 410 stainless blocks, but all, including the coated and plated blocks, showed some tendencies towards growth. Disadvantageously, the coefficients of thermal expansion and conductivity are somewhat lower than desirable.

TABLE 6 . The stability of gage blocks over a one year period, in order of merit

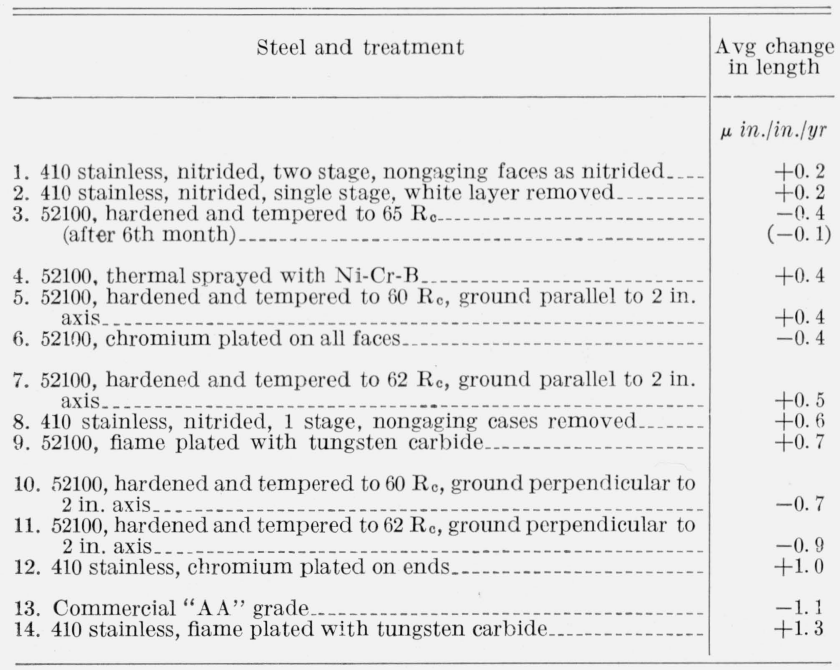

The best of the blocks made from 52100 were those hardened and stabilized at the high hardness of 65 $R_{c}$. The repetition obtained within this group was excellent, and included both directly quenched and martempered blocks. If the first 6 months after final heat treatment are disregarded, these blocks exhibited even greater stability than the best of the 410 stainless. All of the hardened 52100 blocks on which observations were made during the first 6 months contracted initially and then stopped contracting, or expanded according to the tempering or grinding treatment given them.
Several of the blocks with hard coatings were more stable than the commercial blocks tested. Both the sprayed Ni-Cr-B and the plated tungsten carbide apparently caused an overall growth, but on the 52100 blocks the growth was small or had subsided. The principal undesirable feature noted with the Ni-Cr-B and tungsten carbide coatings was the high porosity of surface obtained on lapping, which was readily apparent to the unaided eye.

\section{b. On Precision of Length Measurements}

Three types of measurement were employed in determining the length of the stability samples:

1. Absolute interferometric measurement in which the length of the primary master was determined with the wavelength of light.

2. Interferometric comparison measurement in which the lengths of the secondary masters were compared with the length of the primary master using the wavelength of light as a length scale.

3. Mechanical comparisons of the 10 stability samples of a group with the secondary master belonging to that group.

Of the various types of measurement, the absolute measurement was the most difficult and the least precise for reasons mentioned in section 5.1. Because absolute measurements of the primary master were initiated in 1954 and since many measurements have been made at irregular intervals from that time on, it was believed that its stability could be determined to a much greater precision than individual absolute measurements indicated. For instance, the largest deviation of a single measurement from the average of all 33 measurements made since 1954 was $1.2 \mu \mathrm{in}$. The standard deviation of a single reading was 0.55 $\mu$ in. However, in fitting a curve to these data, it became obvious that a cyclic function with a yearly period best fitted the measurements. Using January 1, 1954 as a zero time reference, a curve calculated by the least squares method to fit the measurement data is expressed by the equation:

$$
L=A \sin \left(\frac{2 \pi t}{B}+\phi\right)+C t+D
$$

where $L=$ length deviation from nominal size ( 2 in.)

$A=+0.75 \mu \mathrm{in}$.

$B=12 \mathrm{mo}$

$t=$ time of measurement in months (January $1,1954=0$ )

$\phi=1.19 \pi$

$C=+0.0035 \mu \mathrm{in} . / \mathrm{mo}$

$D=+4.59 \mu \mathrm{in}$.

The standard deviation of all measurements from this curve was $0.28 \mu \mathrm{in}$. with the largest deviation for a single measurement being $0.5 \mu \mathrm{in}$. It was assumed that the instability of this gage block is expressed by the function $\Delta L=C \Delta t$ whereas the sinusoidal variation is an effect due to error in determination of the effective temperature of the gage block. All absolute measurements on this gage block were made using one interferometer occupying one location in a constant temperature room. The temperature of the 
gage block was determined with one junction of a thermocouple held at the surface of the gage block with a spring clip. The other junction of the thermocouple was imbedded in a copper block surrounded by an insulated aluminum-sheathed box. The temperature of the copper block was determined with a platinum resistance thermometer. The temperature of the copper block related to that of the air in the room showed a seasonal variation, and was generally colder than the air in the winter and warmer in the summer. If the effective temperature of the gage block relative to the temperature measured by the thermocouple junction at its surface is analogous to the relationship of the copper block temperature to that of the air, and if the difference in temperature approaches a maximum of $0.05^{\circ} \mathrm{F}$, the cyclic effect can be rationalized.

Based on the assumption that the instability of the primary standard can be expressed as $C \Delta t$, the primary standard, according to measurement, is growing at the rate of $0.04 \mu \mathrm{in}$./yr. It is believed that this value is accurate to within 100 percent. An error of such small magnitude in the determination of the instability of the primary master block would have no significant effect on the stability results of the samples reported.

Interferometric comparison of the primary master with the secondary master blocks (the stability samples serving as references for the groups of stability samples compared mechanically) were made with the interference comparator mentioned in section 5.1. This interferometer has been subjected to much investigation in regard to the precision of its measurements, [16] the uniformity of the wringing films, and the wear resulting from repeated wringings [20]. As a result of these investigations a precision of $\pm 0.2 \mu \mathrm{in}$. has generally been applied to individual comparisons. Stability samples block A, manufacturer 1, figure 14; $\mathrm{T}-337$, figure $15 ; \mathrm{F}-302$, figure 16 ; and $\mathrm{F}-352$, figure 17 are examples of these secondary master blocks.

From the metrological viewpoint, the results obtained with the mechanical comparator employing transducers in tandem were most interesting. Employing the concept of comparison of dynamic lengths and using statistical analysis of the measurement data to evolve the measurement program, it was possible to obtain residual measurement errors having very small spread and nearly normal distribution. Employing intercomparison tests involving 110 separate comparisons of the gage block samples of a group, it was found possible to limit the residual errors to a spread of $\pm 0.6 \mu \mathrm{in}$. The standard deviation $(\sigma)$ of the result of such an intercomparison test was found to be approximately $0.08 \mu \mathrm{in}$. As the residual errors formed a nearly Gaussian distribution, a 99.7 percent confidence limit of random error $(3 \sigma)$ of $\pm 0.24 \mu \mathrm{in}$. was indicated for the results of such an intercomparison test.

As the tests were repeated at periodic intervals, it was possible to test the reliability of the above statistical evaluation of precision. Most measurements of the stability samples reported extended over a period approximating 1 yr. Three different operators were employed and the temperature of the rooms in which tests were conducted varied from a few tenths of a degree to approximately $2^{\circ} \mathrm{F}$. A small advantage in the control of residual error spread seemed to be achieved in using the best temperature-controlled room. One operator's residual error distributions, in general, had more scatter in the tails of the distributions than did the other two operators. No seasonal variations, as appeared in the absolute interferometric measurement of the primary master block, were noticed. It was found that when care was taken to expose the blocks of a group to the same conditions for at least $18 \mathrm{hr}$ prior to an intercomparison test, the consistency of the periodic results were within the limits of the precision calculated from the statistical evaluation, i.e., approximately $0.2 \mu \mathrm{in}$. Figure 13 illustrates the consistency obtained in monthly measurements and also illustrates, by the exception, the effects of treating the gage blocks differently prior to the intercomparison test.

Another indication that precision of the above magnitude is being obtained in mechanical comparison was derived from the results of mechanical comparison tests conducted to determine the thermal coefficient of linear expansion of the gage block samples. In this procedure, intercomparison tests on a group of samples are conducted at two temperatures. From the results of the two tests the magnitude of the changes in the length relationships of the blocks of the group can be determined. Knowing the difference in temperature of the two tests, the coefficients of all the blocks relative to that of the secondary master block of the group can be determined. The coefficient of the secondary master is then measured by interferometric methods (change of length with temperature determined in terms of wavelength of light) and thus the coefficients of all blocks of the group can be calculated. As a cross check on the precision of the mechanical measurement and as a check on the consistency of the calibration of the mechanical comparator, the coefficients of some blocks determined by mechanical comparison techniques were compared with coefficients determined by interferometric methods. In general, the agreement of results of such tests indicated that the length changes resulting from temperature variation as measured by the mechanical comparator were accurate to better than $0.2 \mu \mathrm{in}$.

A result obtained from the investigation of thermal coefficient of expansion is worthy of note. It is reported in the literature that 52100 steel has an approximately 2 percent smaller thermal coefficient of linear expansion in the annealed state than when hardened to $65 \mathrm{R}_{\mathrm{c}}$. It was found in this investigation that this steel hardened to $60 \mathrm{R}_{\mathrm{c}}$ had a thermal coefficient of expansion about 3 percent lower than that hardened to $65 \mathrm{R}_{\mathrm{c}}$ (table 2 ). This was verified by both mechanical comparison and interferometric methods of measurement.

From the history of past interferometric measurements on the primary master; from the conclusions 
of Dexter's work [20] on wear occurring using the interference comparator; and from the fact that interference measurements were made on a relatively infrequent basis, it was concluded that if wear did occur from interferometric measurements, it was negligible. However, no information was available on the wear effects to be expected in the mechanical comparisons. To allow an evaluation of this effect, the frequency of test was changed from weekly to monthly tests. It was reasoned that if wear did have an effect on the measured stability trends of the blocks, a change in the frequency of test would have an effect upon the trends of length changes exhibited by the blocks. Such effects did not occur.

\section{Summary and Conclusions}

1. A program has been described for the development of steel gage blocks with a maximum dimensional change of $2 \times 10^{-7}$ in./in./yr, a degree heretofore unobtainable with consistency. The problem had a dual nature in that procedures for the selection and processing of materials and suitable techniques for measurement to the desired precision were developed simultaneously.

2. The data presented are the result of observations on two steels given a total of 14 treatments, but which represent only a small proportion of the blocks under development or observation. From this total, two treatments applied to 410 stainless steel produced gage blocks with an average and uniform dimensional change of $2 \times 10^{-7} \mathrm{in}$./in./yr. One treatment applied to the 52100 steel produced gage blocks with an extremely high degree of stability $\left(1 \times 10^{-7} \mathrm{in}\right.$./in./yr) after an initial less stable period of 6 months. Although the results indicate that the goal of the investigation may have been met, periods of observation greater than $1 \mathrm{yr}$ are needed to establish the stability characteristics more firmly. Further improvements in the development of materials and measuring techniques seem possible and will be sought. The failure of other treatments of the 410 and 52100 steels to produce equally stable gage blocks in those cases where the treatments were similar except for small modifications, such as direction of grinding or thickness of nitrided case, has suggested other courses of investigation which are being pursued. Other more subtle influences on stability are being studied also, such as influence of residual magnetism (induced by magnetic grinding chuck) and environmental temperature changes.

3. The method of reporting length in inch per inch is a matter of convention and convenience and should not be construed as being directly convertible to any size of gage block, particularly those of less than 1 in. Size effects can influence both the metallurgical and metrological factors and consideration is being given to the investigation of these effects.

4. Mechanical comparators can be used for measurements with a precision approaching $2 \times 10^{-7}$ in. The procedures involved are also applicable to the rapid measurement of a large number of parts of the same nominal size and thermal properties, and therefore can be adapted to industrial applications. Statistical analysis, used in conjunction with the comparator techniques, has application in determining the most suitable procedures and providing continued uniformity in the application of the technique.

The authors have received guidance, advice, encouragement, and technical support from many sources, both at the National Bureau of Standards and from industry. While a complete listing cannot be attempted, we are very grateful to: Irvine C. Gardner, Chief of the Optics and Metrology Division (Retired), who was responsible for the early planning of the program, general guidance in the metrological phases, and extensive coordination between industry and government; James I. Hoffman, Chief of the Metallurgy Division, who provided broad leadership and guidance in the metallurgical phases; Thomas G. Digges and Samuel J. Rosenberg of the Metallurgy Division, whose suggestions and ideas were always beneficial and contributed substantially to the metallurgical development; E. S. Rowland of The Timken Roller Bearing Co., who served as spokesman for the industrial group, contributed many ideas of his own, and was instrumental in obtaining the experimental materials; A. M. Dexter of the Pratt and Whitney Co., Inc., who as a resident guest worker provided invaluable assistance in the initial phases of the measurement program and who subsequently arranged for the lapping of many gage blocks; Norman Silver of the DoAll Co., who contributed much background information of commercial gage block manufacture and was also instrumental in providing lapping facilities; Arthur Strang of the Optics and Metrology Division, for his absolute interferometric length measurements of the primary master block; John Beers and Grace Chaconas of the Optics and Metrology Division, who analyzed specimens for length, parallelism, and flatness; Richard Kirby of the Opties and Metrology Division, for his interferometric determinations of coefficient of thermal expansion; Charles I. Ward, Jr., of the Instrument Shop, who performed nearly all of the grinding and fabrication on some very difficult surfaces; John T. Lynch of the Metallurgy Division, who performed much of the detailed heat treating and nitriding; and Gertrude Davis who typed the manuscript.

\section{Appendix A: Establishment of Optimum Heat Treating Conditions for 52100 Steel}

\section{Specimens of the steel were heat treated by direct} quenching or by martempering followed by various stabilizing treatments. All specimens used for these heat-treating experiments were $1 / 2 \mathrm{in}$. cubes. The retained austenite content was determined by X-ray diffraction on cross sections of the specimens. The method used employed cobalt $\mathrm{K} \alpha$ radiation with iron filtration, a geiger tube detector, and a step-scanning technique. Originally, both the (220) and (311) 
ines of austenite and the (211) line of martensite were used in the computations, but the use of only the (220) line of austenite and the (211) line of martensite produced comparable results and thus eliminated a great deal of laborious step scanning, and in later determinations only these were used. Guided by the results of the X-ray analysis, the treatments were continuously revised until the austenite could no longer be detected. A summary of the treatments and the retained austenite measured as the result of each is shown in table 7 .
Several pertinent observations can be made from these data. The maximum amount of retained austenite measured was about 15 percent and no values were obtained between 8 and 11 percent; the minimum amount obtained ranged from none detected to about 3 percent. There were no values between 3 and 4 percent and the intermediate quantities varied from greater than 4 percent to about 8 percent. These separations facilitate a convenient grouping into specimens with high austenite, 15 to 11 percent; intermediate austenite, 8 to 4 percent; and low austenite, 3 percent to none detected.

TABLE 7. The effect of heat treatment and stabilization on the quantity of retained austenite in small specimens of 52100 steel

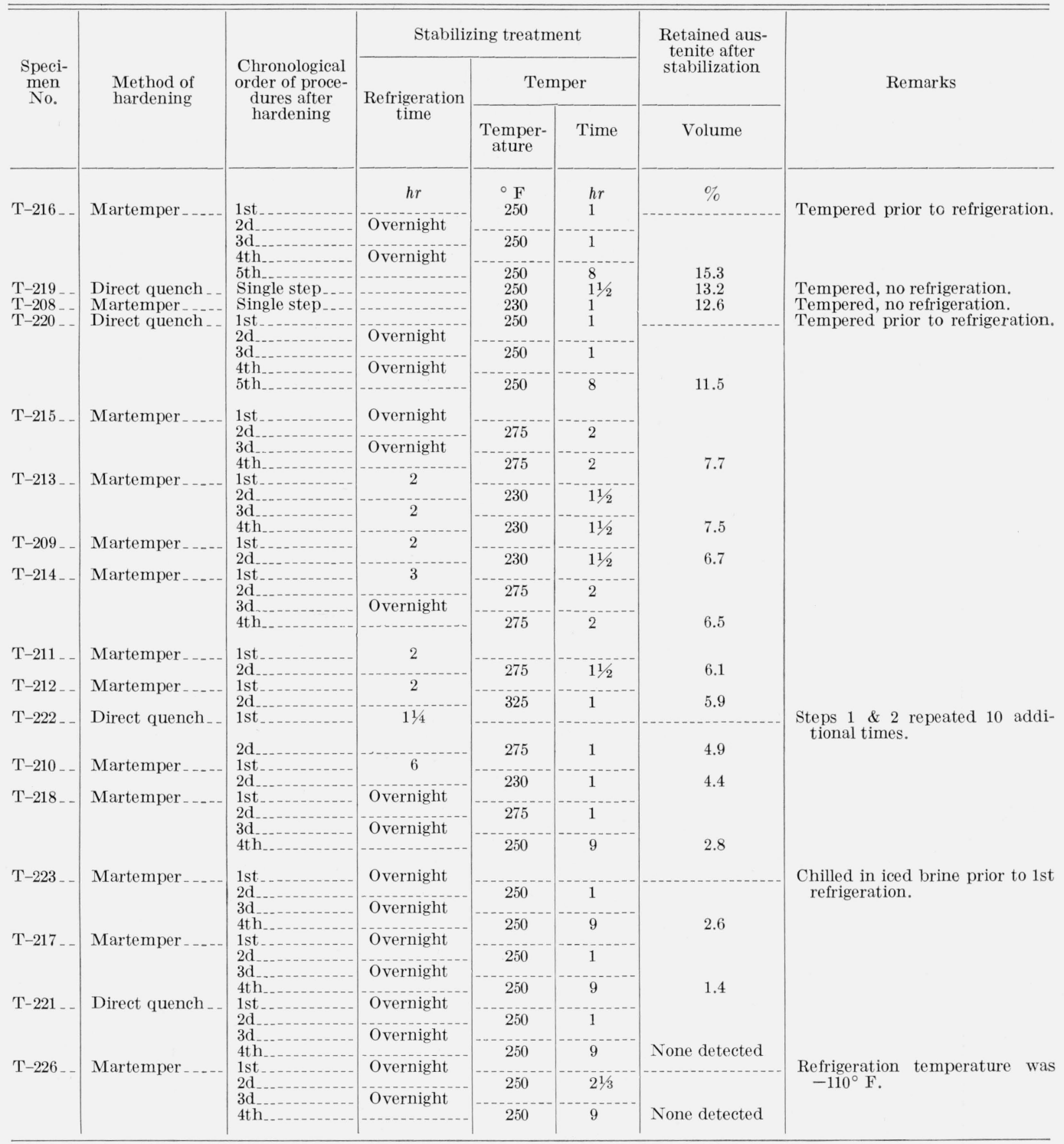

NOTES TO TABLE:

1. All specimens were $1 / 2$ in. cubes austenitized at $1550^{\circ} \mathrm{F}$ for $15 \mathrm{~min}$ in a neutral salt. Martempered specimens were quenched to $300^{\circ} \mathrm{F}$ for $30 \mathrm{sec}$ in a mixture of $\mathrm{NaNO}_{3}$ and $\mathrm{NaNO}_{2}$.

2 . Both the directly quenched and martempered specimens were quenched to room temperature in an accelerated quenching oil

3. Unless otherwise stated, all refrigeration treatments were at $-140^{\circ} \mathrm{F}$. An overnight refrigeration treatment may vary from 18 to $22 \mathrm{hr}$. 
The four specimens in the high austenite group consist of two which were directly quenched and two which were martempered. The treatments given them had one feature in common; they were tempered immediately after hardening. No other specimen received this treatment and there is no doubt that it was responsible for stabilizing the retained austenite against substantial further transformation.

The specimens in the intermediate group received a variety of stabilization treatments; however, all were refrigerated at $-140^{\circ} \mathrm{F}$ as a first step after hardening. The length of time of refrigeration was varied from overnight (18 to $22 \mathrm{hr}$ ) to $1 \frac{1 / 4}{\mathrm{hr}}$. The number of tempers and the temperatures used varied as did the number of refrigeration treatments. However, it is significant to note that most received individual refrigeration treatments of short duration (exception $\mathrm{T}-215$ ) and tempers totaling $4 \mathrm{hr}$ or less (exception T-222). None, including the two excepted specimens, received long time refrigeration treatments, combined with tempering treatments of more than $9 \mathrm{hr}$ at the temperatures shown.

The specimens in the low austenite category, 3 percent or less, have several common treatments. All were refrigerated for 18 to $22 \mathrm{hr}$ immediately after hardening, all were tempered initially at 250 to $275^{\circ} \mathrm{F}$, all were refrigerated a second time for 18 to $22 \mathrm{hr}$, and all were given a final temper of $250^{\circ} \mathrm{F}$ for $9 \mathrm{hr}$. The slight variations in treatment given to each are shown in table 7 and seem relatively unimportant. The important features are a refrigeration of -110 to $-140^{\circ} \mathrm{F}$ for 18 to $22 \mathrm{hr}$ immediately after hardening, a short temper of 1 to $2 \mathrm{hr}$ at $250^{\circ} \mathrm{F}$, a second refrigeration for 18 to $22 \mathrm{hr}$, and a final temper of $9 \mathrm{hr}$. The total prescribed tempering time of $10 \mathrm{hr}$ was selected to conform with the conclusions advanced by Lement, Averbach, and Cohen [9] for ball bearing steel.

On the basis of these data, the treatment given specimen T-221 was adopted for use with directly quenched gage blocks and that given T-217 for martempered blocks. The stabilizing treatment used with T-217 was adopted over that used with T-226 because of its similarity to that of $\mathrm{T}-221$ and the convenience inherent in such an arrangement.

Another series of heat and stabilization treatments was devised for 2 in. $\times 1 \frac{3 / 8}{8}$ in. $\times 3 / 8$ in. gage blocks to test the validity of the adopted treatments on full sized gage blocks, and to evaluate other variables. The treatments and the result of measurements of retained austenite are summarized in table 8 . The readiness with which some austenite becomes stabilized with delay in treatment is shown in a number of cases. For example, block T-323 was treated similarly to small specimen T-217 and in almost the same manner as block T-333, except for a $48 \mathrm{hr}$. lapse between the final refrigeration and final temper of T-323. T-323 had a considerably greater amount of retained austenite. Shorter delays also appear injurious, as for example, in the comparison of specimens T-223 and T-217 (table 7). T-223 was held in iced brine for $2 \mathrm{~min}$ immediately after quenching to room temperature in oil, and then it was placed in liquid $\mathrm{CH}_{3} \mathrm{OH}$ (methyl alcohol) at $-140^{\circ} \mathrm{F}$. On the other hand, $\mathrm{T}-217$ went into the $\mathrm{CH}_{3} \mathrm{OH}$ directly without the opportunity to age at a higher temperature and it contains less austenite. The same trend is indicated between blocks T-328 and T-331 (table 8). Blocks T-329 and T-332 contained somewhat more austenite than small specimen $\mathbf{T}-221$ which was treated in the same way, and this may have been caused by the difference in cooling rate between the larger blocks and smaller specimen.

The greater austenite content may also have been caused by the differences in stress distribution in the differently sized and shaped specimens. To avoid difficulties from delays, a cold mixture $\left(\mathrm{CH}_{3} \mathrm{OH}+\right.$ liquid $\mathrm{N}_{2}$ at equilibrium, $\left.-144^{\circ} \mathrm{F}\right)$ was brought to the quenching tank and the blocks placed therein immediately after quenching. The cold container with the blocks was then transferred to the refrigeration unit where the temperature was maintained at $-140^{\circ} \mathrm{F}$ for the required time. This is the two step refrigeration treatment listed in table 8 .

It was pointed out in the discussion of table 7 that no specimen with intermediate austenite had received a combination of long time refrigeration treatments and tempering treatments exceeding $9 \mathrm{hr}$. To further check the necessity of long refrigerating time, while tempering time was held at $10 \mathrm{hr}$, block $\mathrm{T}-335$ was given comparatively short time refrigeration treatments at $-140^{\circ} \mathrm{F}$ and $\mathrm{T}-336$ was given short time treatments at $-110^{\circ} \mathrm{F}$. Both had negligible amounts of retained austenite.

It was concluded from these tests on the 52100 treated for minimum retained austenite and a hardness of about $65 \mathrm{R}_{\mathrm{c}}$ that:

1. Refrigeration is a necessary first step immediately after hardening.

2. Stabilizing treatments should be accomplished with the least possible delay between steps.

3. Refrigeration temperatures in the range $-110^{\circ}$ to $-140^{\circ} \mathrm{F}$ are equally satisfactory, and two treatments in this range are ample.

4. The time of holding at refrigeration temperature can be as short as $2 \mathrm{hr}$ for the initial treatment and $3 \mathrm{hr}$ for the second treatment.

5 . A first temper of $1 \mathrm{hr}$ at $250^{\circ} \mathrm{F}$ appears adequate, an extension of this temper beyond $2 \mathrm{hr}$, or above $250^{\circ} \mathrm{F}$, may induce some stabilization of austenite.

6. A final temper of $9 \mathrm{hr}$ at $250^{\circ} \mathrm{F}$ or slightly higher is adequate.

\section{Appendix B: Hard Coatings, Description, and Application}

\subsection{Thermal Spray}

The thermal spraying process consists of melting or softening a wire or powder in a suitable gun and directing the spray of liquid or softened particles onto the surface to be coated. The alloy used was a 
TABLE 8. The effect of heat treatment and stabilization on the amount of retained austenite in gage blocks of 52100 sieel

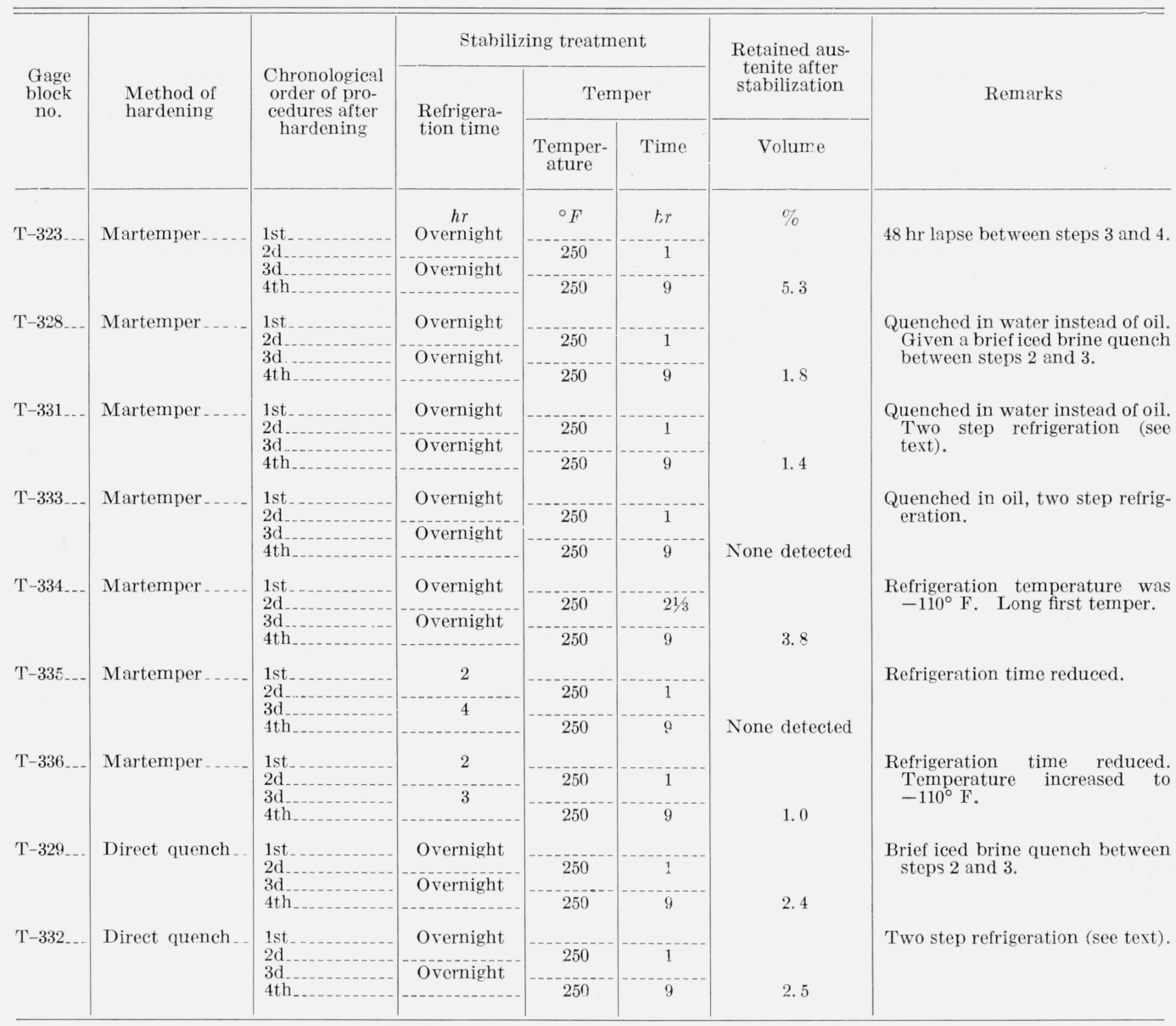

\section{NOTES TO TABLE:}

1. All gage blocks were nominally 2 in. $\times 13 / 8 \mathrm{in} . \times^{3} / 8 \mathrm{in}$. in size, austenitized at $1550^{\circ} \mathrm{F}$ for $15 \mathrm{~min}$ in a neutral salt. Martempered specimens were quenched to $300^{\circ} \mathrm{F}$ for $30 \mathrm{sec}$ in a mixture of $\mathrm{NaNO}_{3}$ and $\mathrm{NaNO}_{2}$

2. Both the directly quenched and martempered blocks were quenched to room temperature in an accelerated quenching oil except where water is noted in the remarks column.

3. Unless otherwise stated, all refrigeration treatments were at $-140^{\circ} \mathrm{F}$. An overnight refrigeration treatment may vary from 18 to $22 \mathrm{hr}$.

self-fluxing alloy of nickel, chromium, and boron sold commercially as Thermospray ${ }^{9}$ powder $16 \mathrm{C}$. It was applied by a commercial firm to a thickness of about 0.015 in. on each gaging face. After lapping, the final thickness was $0.006 \mathrm{in.}$ The coating required a fusing treatment after application and this was done by the firm, but the exact temperature to which the blocks were heated could not be ascertained. The hardness of the coating was measured as $62 R_{\text {c }}$ (converted from Vickers, $10 \mathrm{~kg}$ ). After grinding and lapping, the surface of the coating appeared more porous than a wrought metal. A photomicrograph of the coating is shown in figure $18 \mathrm{~A}$.

\subsection{Flame Plate}

The flame plating process is somewhat similar to the thermal spray process, but its use is generally limited to the application of refractory alloys or

\footnotetext{
${ }^{9}$ Trademark of the Metallizing Equipment Co., Inc.
}

ceramics, and with these materials a fusing treatment is not used. The coating is applied at supersonic velocities and is propelled by a controlled detonation within the barrel of the gun. The manufacturer claims that the surface of the piece being coated rarely exceeds $400^{\circ} \mathrm{F}$. All flame plating was done by the originator of the process. ${ }^{10}$ Both the tungsten carbide and the aluminum oxide coatings were applied to each gaging surface to a thickness of about 0.004 in. The thickness of the coating on each, after lapping, was on the order of $0.0025 \mathrm{in}$. After lapping, considerable porosity could be observed in each of these coatings with the unaided eye. The tungsten carbide coating contains about 8 percent of cobalt, whereas the $\mathrm{Al}_{2} \mathrm{O}_{3}$ is $99+\% \mathrm{Al}_{2} \mathrm{O}_{3}$. Hardness of both coatings is far in excess of $65 \mathrm{R}_{\mathrm{c}}$. The coefficients of thermal expansion of both of these coatings are considerably lower than steel, and are given by the manufacturer as $2.89 \times 10^{-6} /{ }^{\circ} \mathrm{F}\left(70^{\circ}\right.$ to

${ }_{10}$ Linde Air Products Co. 

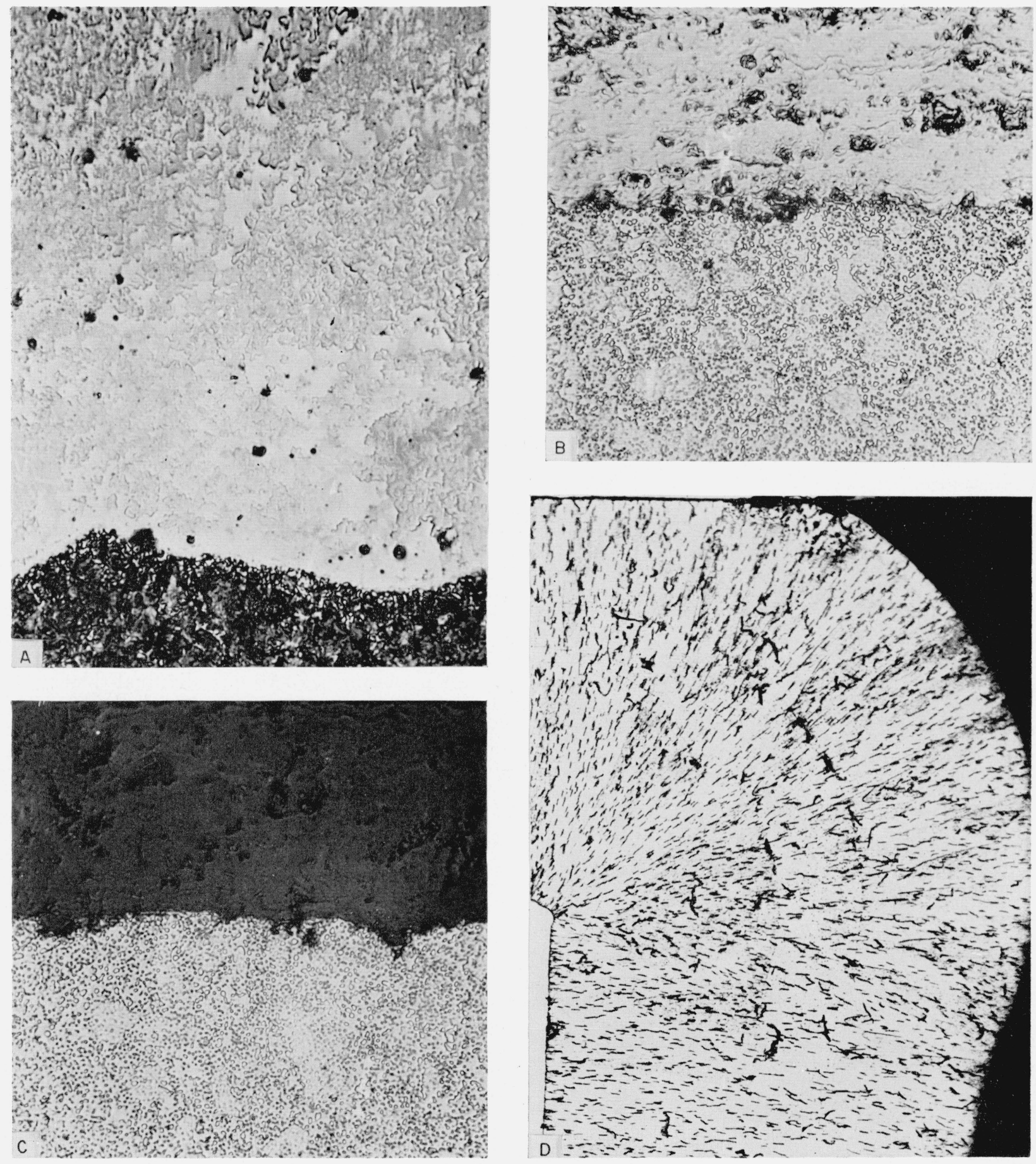

FiguRE 18. Microstructures of hard coatings.

All except the chromium have been ground and lapped to final thickness. The chromium is shown as plated and stress relieved.

A. Thermal sprayed Ni-Cr-B on 52100 steel. Etched with $1 \%$ Nital. $\times 500$

B. Flame plated tungsten carbide on 52100 steel. Etched with $1 \%$ Nital. $\times 500$

D. Chromium plate on D-2 tool steel. Etched with HCl. $\times 200$. White area at lower left is a corner of the steel block. 
$\left.150^{\circ} \mathrm{F}\right)$ for tungsten carbide and $4.0 \times 10^{-6} /{ }^{\circ} \mathrm{F}(100$ to $\left.2,000^{\circ} \mathrm{F}\right)^{11}$ for aluminum oxide. Photomicrographs of these two coatings are shown in figures $18 \mathrm{~B}$ and $\mathrm{C}$.

\subsection{Chromium Plate}

Chromium was applied directly over the steels by conventional electroplating techniques. The bath consisted of $0.53 \mathrm{oz}$ (avdp) of sulfuric acid and 53 $\mathrm{oz}$ (avdp) of chromic acid per gallon of water. Current density was 180 to $190 \mathrm{amp} / \mathrm{ft}^{2}$ and bath temperature was $120^{\circ} \mathrm{F}$. The 52100 steel was plated on all surfaces and the 410 stainless was plated on the gaging surfaces only. The minimum thickness of the plating as applied was about $0.010 \mathrm{in}$. The finished thickness on the gaging faces and on the nongaging faces, when applied, was 0.005 in. Tests were run to ascertain the temperatures to which the plating could be subjected for the removal of hydrogen and for stress relief. As plated, the hardness was $68 \mathrm{R}_{\mathrm{c}}$ (converted from Knoop, $500 \mathrm{~g}$ ) which did not fall below $65 \mathrm{R}_{\mathrm{c}}$ until a temperature in excess of $820^{\circ} \mathrm{F}$ was used. However, at this high temperature hairline cracks appeared in the plating, which were attributed to stresses caused by the differential thermal expansion of the block and the plating. A stress relieving temperature of $400^{\circ} \mathrm{F}$ for $5 \mathrm{hr}$ was adopted to prevent cracking. A photomicrograph of the plated chromium after stress relieving at $820^{\circ} \mathrm{F}$ is shown in figure $18 \mathrm{D}$. In appearance, it does not differ from the as-deposited coating.

\section{Appendix C: Grinding Procedures and Other Details of Fabrication}

\subsection{0, Hardened}

All of the 52100 blanks were ground to $2.04 \mathrm{in}$. $\times 1.39$ in. $\times 0.39$ in prior to hardening and stabilization. After completion of the heat treatment, all

11 The lower value for the coefficient of thermal expansion reported in table 2 was measured on solid $\mathrm{Al}_{2} \mathrm{O}_{3}$ blocks supplied by another manufacturer. but four of the blocks were ground to size on the four largest faces in a direction parallel to the $2 \mathrm{in}$. direction. The four excepted blocks (T-377, T-378, $\mathrm{T}-384, \mathrm{~T}-386$ ) were ground on the four largest faces in a direction perpendicular to this dimension. The grinding wheel used and the operational settings of the surface grinder are given in table 9 .

After final grinding the blocks were stress relieved for $3 \mathrm{hr}$ at the temperatures shown in table 4, and sent to a commercial firm for lapping. The surfaces of the lapped blocks were surveyed for parallelism and flatness, some blocks were used for thermal expansion or other measurements, and the best of each lot as to parallelism and flatness were incorporated in the measuring program.

\subsection{Stainless, Nitrided}

All 410 stainless blanks were ground to a length of $2.0050 \mathrm{in}$., but the width and thickness were varied so as to permit finishing to 1.375 in. $\times 0.375$ in., since some of the surfaces received no grinding after nitriding and others received different amounts. Blanks intended for two stage nitriding, and on which the nongaging faces were to be left as nitrided, were ground to $1.374 \mathrm{in} . \times 0.374 \mathrm{in}$.; blanks on which only the frosty coating was to be removed were ground to $1.375 \mathrm{in} . \times 0.375 \mathrm{in}$.; and blanks on which the cases on nongaging faces were to be completely removed were made about 1.430 in. $\times 0.430$ in. (earlier blocks were slightly smaller). Details of the nitriding treatments given individual blocks are shown in table 4. After nitriding, all three series of 410 blocks were ground to 2.0030 in. and two series were ground on the 4 nongaging surfaces to a width of $1.375 \mathrm{in}$. and a thickness of 0.375 in. Additional grinding details are given in table 9 .

All of the nitrided 410 blocks were stress relieved at $975^{\circ} \mathrm{F}$ for $3 \mathrm{hr}$ after grinding and before sending to commercial firms for lapping. The final hardness of the cases and the dates of the final stress reliefs are included in table 4 . The blocks were then lapped commercially and the most suitable of each lot placed in the measuring program.

TABLE 9. Details for grinding the hardened and coated gage blocks

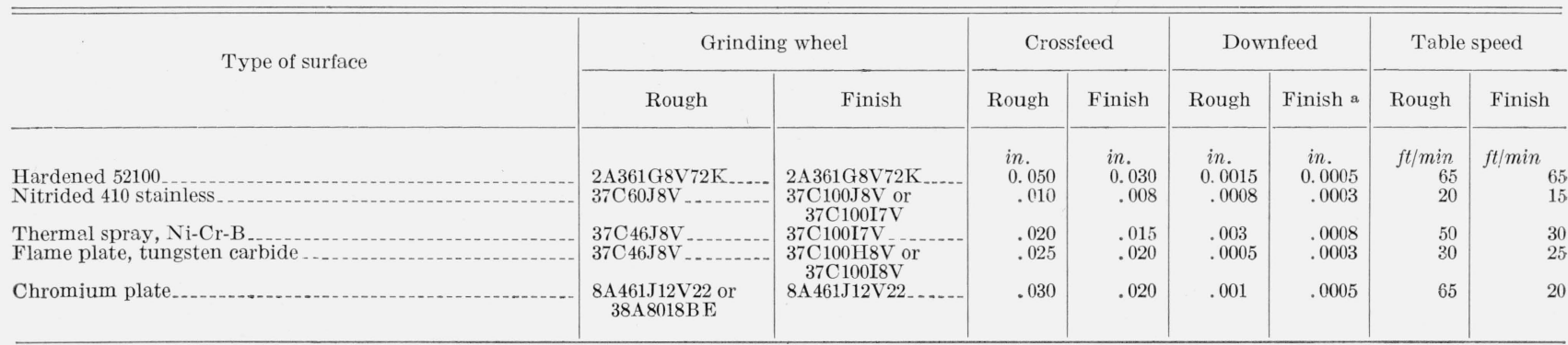

a These values are for gaging surfaces and should be increased by about 50 percent on nongaging surfaces.

Notes to Table:

1. The nongaging faces of all blocks except four (T-377, T-378, T-384, T-386) were ground parallel to the 2 in. dimension. The four excepted blocks were ground perpendicular to the 2 in. direction.

2. The grinding wheel speed was $2300 \mathrm{RPM}$. All wheels were $10 \mathrm{in}$. in diam when new and were discarded when worn to about 6 in. All wheels were $3 / 4$ in. to 1 in. thick.

3. All grinding was done wet with White-Bagely WB-1500 solution diluted with water to approximately 150 parts of water per 1 part solution.

4. Downfeed was changed from rough to finish when 0.0005 in. of stock remained to be removed from each gaging surface and 0.002 in. to 0.005 in. remained on each nongaging surface. 


\subsection{Blocks With Hord Coatings}

\section{a. Thermal Spray}

The 52100 steel blanks were ground to 1.987 in. $\times 1.375$ in. $\times 0.375$ in., and the nickel-chromiumboron coating applied on the gaging faces only to a thickness of about 0.015 in. The blocks were then ground in the same directions as described for the hardened 52100 blocks. The four nongaging surfaces were ground just sufficiently to remove the black scale formed during the fusing treatment. The gaging surfaces were ground to reduce overall length to $2.0030 \mathrm{in}$., leaving equal thickness of coating on each face. Further grinding details are given in table 9 . After grinding, the blocks were stress relieved as shown in table 4, and sent to a commercial firm for lapping.

\section{b. Flame Plate}

The 52100 and the 410 stainless blanks were ground to $1.995 \mathrm{in} . \times 1.375 \mathrm{in} . \times 0.375 \mathrm{in}$. prior to coating the gaging surfaces to a thickness of about $0.004 \mathrm{in}$. The nongaging surfaces were not coated. The surfaces were ground to reduce overall length to 2.0030 in., leaving equal thickness of coating on each face. Additional grinding details are given in table 9 . The nongaging faces were not ground after plating. The blocks were stress relieved as shown in table 4 prior to lapping.

\section{c. Chromium Plate}

It is a characteristic trait of the chromium plating process that thicker deposits of metal build up at sharp outside corners. Such a build up is shown in the photomicrograph in figure 18D. This condition makes necessary the careful alinement of the block in the grinding chuck to prevent the plating from being ground nonparallel to the underlying surface with a resultant nonuniform thickness of plating. This in turn can cause opposite gaging faces which are parallel at one temperature to become nonparallel at another temperature, particularly if the nongaging faces of the gage block are plated and ground nonuniformly. The need for extremely close control to avoid this condition can be eliminated by plating the gaging surfaces only. The 52100 blanks were ground to 1.990 in. $\times 1.365$ in. $\times 0.365$ in. prior to plating on all surfaces and the 410 stainless blanks were ground to 1.990 in. $\times 1.380$ in. $\times 0.380$ in. for plating on the gaging faces only. The blanks were stress relieved at $975^{\circ} \mathrm{F}$ for $3 \mathrm{hr}$ in a cracked ammonia atmosphere prior to plating. After plating, each block was ground to 2.0030 in. $\times 1.375$ in. $\times 0.375$ in. in accordance with the details given in table 9. After grinding the blocks were stress relieved at $400^{\circ} \mathrm{F}$ for $5 \mathrm{hr}$ in a cracked ammonia atmosphere and sent to a lapping firm for the final step in processing.

\section{Appendix D: Nullification of Effects of Inhomogeneous, Nonlinear Measurement Error}

One method that may be used in refining the intercomparison testing technique is to arrange the sequence of comparisons to annul the effects of measurement error. This can be illustrated by the following example. Consider the four test specimens, gage blocks $A, B, C, D$ in table 10 to have lengths $a, b, c$, and $d$ respectively. Consider the systematic error in the comparator reading to be a function of time with slope $\alpha_{t}$, as shown in figure $19,{ }^{12}$ and for the present ignore random errors. If the time interval of one comparison of a pair of gage blocks is $\Delta t$, the systematic error in a comparison occurring at time $t$ is $\alpha_{t} \Delta t$. However, the curve shown in figure 19 may be approximated by $(n-1)$

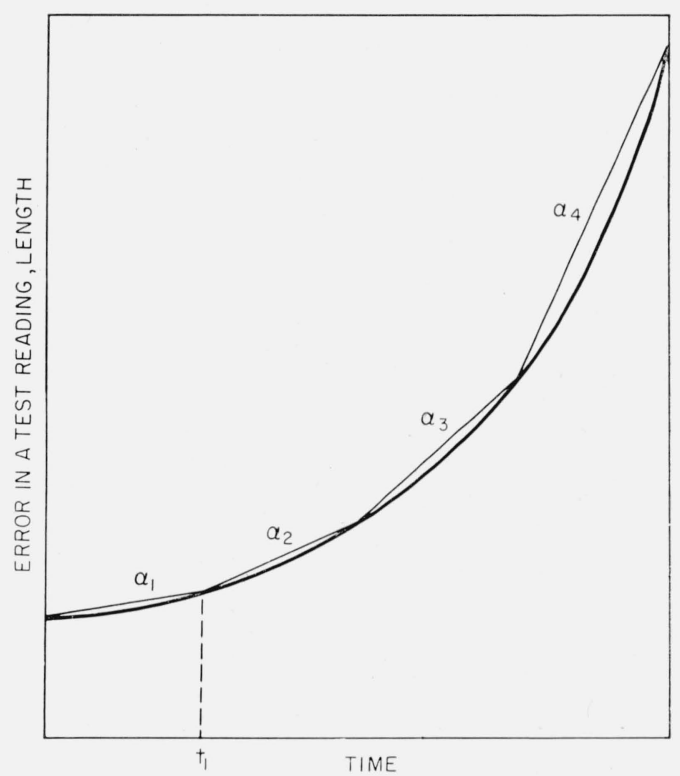

FIgURE 19. A hypothetical nonlinear error function and its approximation by a number of linear segments.

linear segments having slopes $\alpha_{1}, \alpha_{2}, \alpha_{3}, \ldots \alpha_{(n-1)}$ where $n$ is the number of gage blocks in the group being intercompared, four in this example. The subscripts refer to periods of time in which $n$ comparisons are made. If the interval of each comparison is again $\Delta t$, the errors occurring during the comparisons can be approximated by $\alpha_{1} \Delta t, \alpha_{2} \Delta t, \alpha_{3} \Delta t$, . . $\alpha_{(n-1)} \Delta t$. By arranging the sequence of comparisons these systematic errors may be distributed so that they are approximately nullified in the results obtained by means of the type of calculation illustrated in table 5. That is, if the sequence of comparisons is so arranged that each column contains equal increments of the systematic errors, then the column footings will contain equal amounts of

12 This function need be continuous only during the time of each individual comparison. 
such error and in that event computation by means of the method illustrated by table 5 will provide results in which these errors are nullified. Table 10 illustrates comparison data obtained when such a sequence of comparisons is utilized. ${ }^{13}$ The circled numbers in table 10 indicate the sequence in which the comparisons were made. The residuals obtained with this sequence of comparison and utilizing the type of computation illustrated in table 5 , would be grouped equally at $\alpha_{1} \Delta t, \alpha_{2} \Delta t$, and $\alpha_{3} \Delta t$. It will be noticed that with this sequence (table 10) these systemmatic errors may also be eliminated from the residuals as well as from the results by applying the least squares type of solution. This is because the comparisons symmetrical to the diagonal (table 10) are made in the same time period (while $\alpha$ remains constant), in fact one immediately following the other.

This latter requirement may introduce the necessity of further modification. With two comparisons of the same gage blocks being performed in a short time interval, thermal effects of handling in the first comparison may modify the error function in the second comparison so that two error functions exist; i.e., inhomogeneous comparison data are obtained. It was reasoned that if the second comparison always followed the first by a constant time interval, and if the handling of the gage blocks during the two comparisons was always consistent, then the two error functions would differ by a fixed amount. If $\alpha_{11}, \alpha_{21}, \alpha_{31}, \ldots \alpha_{(n-1) 1}$ refer to the slopes of the first error function in the time periods $1,2,3, \ldots$ $(n-1)$ respectively, and $\alpha_{12}, \alpha_{22}, \alpha_{32}, \ldots \alpha_{(n-1) 2}$ refer to slopes of the second error function during these same time periods, then:

$$
\begin{array}{r}
\left(\alpha_{11}-\alpha_{12}\right) \Delta t=\left(\alpha_{21}-\alpha_{22}\right) \Delta t=\left(\alpha_{31}-\alpha_{32}\right) \Delta t \\
=. .\left(\alpha_{(n-1) 1}-\alpha_{(n-1) 2}\right) \Delta t=k \Delta t
\end{array}
$$

To eliminate this type of error from the final results of an intercomparison test there should exist, as was said above, an equal magnitude of error effect in each column of the calculation chart. For a group of $n$ specimens there will be $n(n-1)$ comparisons in the intercomparison test; $n(n-1) / 2$ comparisons of

${ }^{13}$ If $\alpha$ is constant, that is if $\alpha_{1}=\alpha_{2}=\alpha_{3}=\ldots \alpha$ (n-1) then the systematic errors are nullified regardless of the sequence in which the comparisons are made since the equal increments of error always appear in each column. the first type, and an equal number of comparisons of the second type. If there is to be an equal number of comparisons of each type in a column, $(n-1) / 2$ comparisons of a type should appear in a column. As this number must be an integer, $n$ must be odd.

Table 11 indicates an intercomparison test schedule that would approximately nullify two nonlinear error functions in the final results, an additional gage block has been added to the group to fulfill the requirement that $n$ be odd. Spaces containing two approximately equal values represent comparisons made at times when the error function could be indicated by either of two slopes; e.g., at time $t_{1}$ in figure 19 .

Using eq (1) relating the error functions, the values indicated in table 12 are obtained from those shown in table 11. It will be noted that in the summations of each column of table 12 the amounts of systematic error are equal. This also holds true if a least squares type of solution is applied to the data in table 12 . This is shown in table 13 where this method of computation is employed. Here the systematic error is cancelled within each column so that the column footings equally contain no systematic error. Thus employing either method of computation with this sequence of comparisons, appropriate comparison of the column footings provides the true relationships of the gage blocks even though inhomogeneous, nonlinear error functions are present in the observed measurements. The precision of the results obtained by the least squares method is, of course, greater than that obtained with the method of computation illustrated in table 5. Further, an examination of the residuals obtained with the two different methods of computation will indicate another reason for utilizing the least squares method. The residuals obtained from table 12 using the method of calculation illustrated in table 5 are given in table 14 . It can be seen that residuals of various magnitude are obtained, the magnitude depending on the value of the two error functions (assuming $\Delta t$ is constant). On the other hand, when the least squares method of computation is employed (table 13) the residuals shown in table 15 are obtained. It is obvious here that the magnitude of the residuals is dependent only upon the difference between the two error functions (again assuming $\Delta t$

\begin{tabular}{|c|c|c|c|c|}
\hline Blocks & $A$ & $B$ & C & $D$ \\
\hline$A$ & * & (1) $b-a+\alpha_{1} \Delta t$ & (9) $c-a+\alpha_{3} \Delta t$ & (7) $d-a+\alpha_{2} \Delta t$ \\
\hline$B$ & (2) $a-b+\alpha_{1} \Delta t$ & * & (5) $c-b+\alpha_{2} \Delta t$ & (11) $d-b+\alpha_{3} \Delta t$ \\
\hline$C$ & (10) $a-c+\alpha_{3} \Delta t$ & (6) $b-c+\alpha_{2} \Delta t$ & $*$ & (3) $d-c+\alpha_{1} \Delta t$ \\
\hline$D$ & (8) $a-d+\alpha_{2} \Delta t$ & (12) $b-d+\alpha_{3} \Delta t$ & (4) $c-d+\alpha_{1} \Delta t$ & * \\
\hline$\Sigma$ & $3 a-b-c-d+\sum_{n=1}^{3} \alpha_{n} \Delta t$ & $3 b-a-c-d+\sum_{n=1}^{3} \alpha_{n} \Delta t$ & $s c-a-b-d+\sum_{n=1}^{3} \alpha_{n} \Delta t$ & $3 d-a-b-c+\sum_{n=1}^{3} \alpha_{n} \Delta t$ \\
\hline$\Sigma / 4$ & $1 / 4\left(3 a-b-c-d+\sum_{n=1}^{3} \alpha_{n} \Delta t\right)$ & $1 / 4\left(3 b-a-c-d+\sum_{n=1}^{3} \alpha_{n} \Delta t\right)$ & $1 / 4\left(3 c-a-b-d+\sum_{n=1}^{3} \alpha_{n} \Delta t\right)$ & $1 / 4\left(3 d-a-b-c+\sum_{n=1}^{3} \alpha_{n} \Delta t\right)$ \\
\hline
\end{tabular}

TABLE 10. Sequence of comparisons arranged to nullify effects of a nonlinear error function in an intercomparison test 
TABLE 11. Intercomparison test schedule nullifying the effects of two nonlinear error functions

\begin{tabular}{c|c|c|c|c|c}
\hline \hline Blocks & $A$ & $B$ & $C$ & $D$ \\
\hline$A$ & $*$ & (2) $b-a+\alpha_{12} \Delta t$ & (18) $c-a+\alpha_{32} \Delta t$ & (15) $d-a+\alpha_{31} \Delta t$ & (5) $e-a+\alpha_{11} \Delta t$ \\
$B$ & (1) $a-b+\alpha_{11} \Delta t$ & $c-b+\alpha_{22} \Delta t$ & (20) $d-b+\alpha_{42} \Delta t$ & (13) $e-b+\alpha_{31} \Delta t$ \\
$C$ & $\begin{array}{c}a-c+\alpha_{21} \Delta t \\
\text { (11) } \approx a-c+\alpha_{31} \Delta t\end{array}$ & (7) $b-c+\alpha_{21} \Delta t$ & (4) $d-c+\alpha_{12} \Delta t$ & (18) $e-c+\alpha_{42} \Delta t$ \\
$D$ & $\begin{array}{c}a-d+\alpha_{32} \Delta t \\
\text { (16) } \approx a-d+\alpha_{12} \Delta t \\
a-e+\alpha_{12} \Delta t\end{array}$ & (19) $b-d+\alpha_{41} \Delta t$ & (3) $c-d+\alpha_{11} \Delta t$ & $*$ & (10) $e-d+\alpha_{22} \Delta t$ \\
$E$ & (14) $b-e+\alpha_{32} \Delta t$ & (11) $c-e+\alpha_{41} \Delta t$ & (3) $d-e+\alpha_{21} \Delta t$ & $*$ \\
\hline
\end{tabular}

TABLE 12. Result of application of equation (1) to values in table 11, indicating equalization of error in column footings

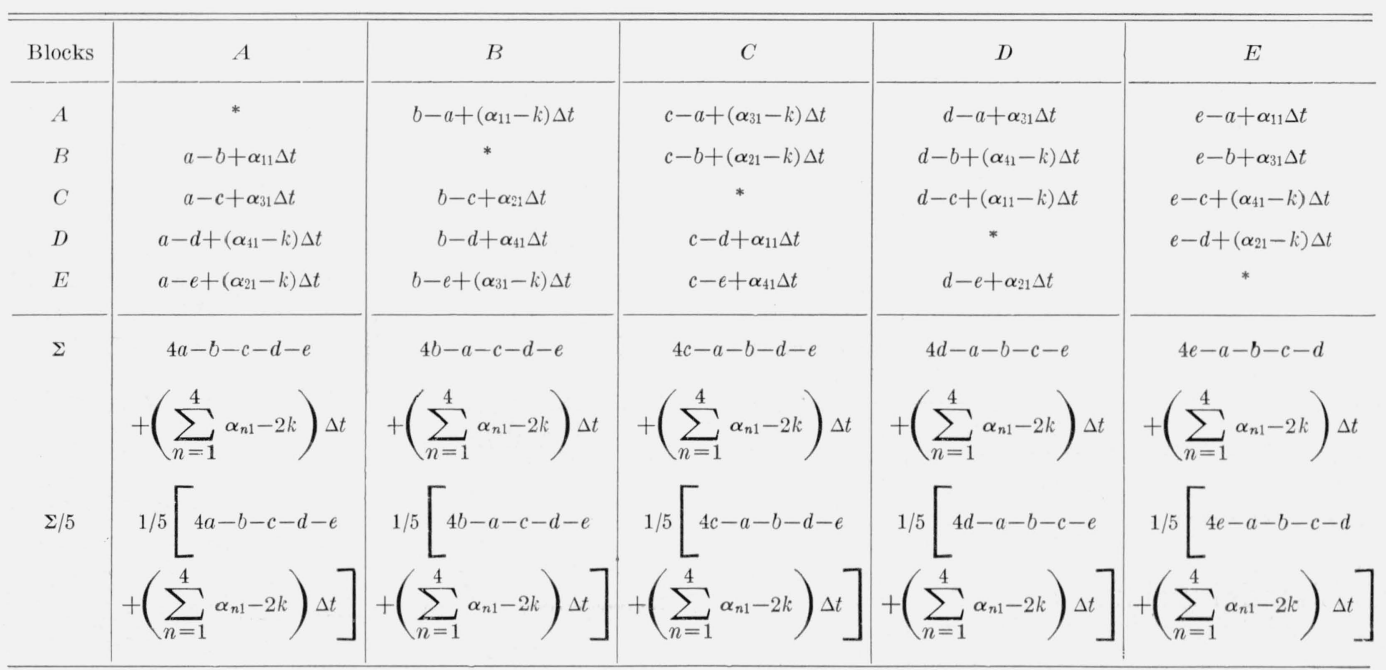

TABLE 13. Result of applying least squares type of solution to data in table 12

\begin{tabular}{|c|c|c|c|c|c|}
\hline Blocks & $A$ & $B$ & $C$ & $D$ & $E$ \\
\hline$A$ & * & $b-a-\frac{k \Delta t}{2}$ & $c-a-\frac{k \Delta t}{2}$ & $d-a+\frac{k \Delta t}{2}$ & $e-a+\frac{k \Delta t}{2}$ \\
\hline$B$ & $a-b+\frac{k \Delta t}{2}$ & $*$ & $c-b-\frac{k \Delta t}{2}$ & $d-b-\frac{k \Delta t}{2}$ & $e-b+\frac{k \Delta t}{2}$ \\
\hline$C$ & $a-c+\frac{k \Delta t}{2}$ & $b-c+\frac{k \Delta t}{2}$ & $*$ & $d-c-\frac{k \Delta t}{2}$ & $e-c-\frac{k \Delta t}{2}$ \\
\hline$D$ & $a-d-\frac{k \Delta t}{2}$ & $b-d+\frac{k \Delta t}{2}$ & $c-d+\frac{k \Delta t}{2}$ & $*$ & $e-d-\frac{k \Delta t}{2}$ \\
\hline$E$ & $a-e-\frac{k \Delta t}{2}$ & $b-e-\frac{k \Delta t}{2}$ & $c-\epsilon+\frac{k \Delta t}{2}$ & $d-\epsilon+\frac{k \Delta t}{2}$ & * \\
\hline$\Sigma$ & $4 a-b-c-d-e$ & $4 b-a-c-d-e$ & $4 c-a-b-d-e$ & $4 d-a-b-c-e$ & $4 e-a-b-c-d$ \\
\hline$\Sigma / 5$ & $1 / 5(4 a-b-c-d-e)$ & $1 / 5(4 b-a-c-d-e)$ & $1 / 5(4 c-a-b-d-e)$ & $1 / 5(4 d-a-b-c-e)$ & $1 / 5(4 e-a-b-c-d)$ \\
\hline
\end{tabular}

is constant). This means that the residual distributions obtained when the least squares method of computation is employed will provide a more easily understood indication of inhomogeneity in the data. The fact that the two error functions differ by an amount $k$ can be more readily determined from the residual distribution obtained when the least squares method is employed than when the method of com- putation illustrated in table 5 is used. Thus the method of least squares was adopted for the computation of all test results.

The above discussion assumed the absence of random errors and in that event indicated that if the method of least squares is employed when there are two error functions differing by an amount $k$ present, residuals of $+(k \Delta t / 2)$ and $-(k \Delta t / 2)$ will 
TABLE 14. Residuals obtained by applying to the data in table 12 the method of computation illustrated in table 5

\begin{tabular}{|c|c|c|c|c|c|}
\hline Blocks & $A$ & $B$ & $C$ & $D$ & $E$ \\
\hline$A$ & * & $\left(\alpha_{11}-k\right) \Delta t$ & $\left(\alpha_{31}-k\right) \Delta t$ & $\boldsymbol{\alpha}_{31} \Delta t$ & $\alpha_{11} \Delta t$ \\
\hline$B$ & $\alpha_{11} \Delta t$ & $*$ & $\left(\alpha_{21}-k\right) \Delta t$ & $\left(\alpha_{41}-k\right) \Delta t$ & $\alpha_{31} \Delta t$ \\
\hline$C$ & $\alpha_{31} \Delta t$ & $\alpha_{21} \Delta t$ & * & $\left(\alpha_{11}-k\right) \Delta t$ & $\left(\alpha_{41}-k\right) \Delta t$ \\
\hline$D$ & $\left(\alpha_{41}-k\right) \Delta t$ & $\alpha_{41} \Delta t$ & $\alpha_{11} \Delta t$ & * & $\left(\alpha_{21}-k\right) \Delta t$ \\
\hline$E$ & $\left(\alpha_{21}-k\right) \Delta t$ & $\left(\alpha_{31}-k\right) \Delta t$ & $\alpha_{41} \Delta t$ & $\alpha_{21} \Delta t$ & * \\
\hline
\end{tabular}

TABLE 15. Residuals obtained by applying to the data in table 12 a least squares method of solution

\begin{tabular}{c|c|c|c|c|c}
\hline \hline Blocks & $A$ & $B$ & $C$ & $D$ & $E$ \\
\hline$A$ & $*$ & $-\frac{k \Delta t}{2}$ & $-\frac{k \Delta t}{2}$ & $+\frac{k \Delta t}{2}$ & $+\frac{k \Delta t}{2}$ \\
$B$ & $+\frac{k \Delta t}{2}$ & $*$ & $-\frac{k \Delta t}{2}$ & $-\frac{k \Delta t}{2}$ & $+\frac{k \Delta t}{2}$ \\
$C$ & $+\frac{k \Delta t}{2}$ & $+\frac{k \Delta t}{2}$ & $*$ & $-\frac{k \Delta t}{2}$ & $-\frac{k \Delta t}{2}$ \\
$D$ & $-\frac{k \Delta t}{2}$ & $+\frac{k \Delta t}{2}$ & $+\frac{k \Delta t}{2}$ & $*$ & $-\frac{k \Delta t}{2}$ \\
$E$ & $-\frac{k \Delta t}{2}$ & $-\frac{k \Delta t}{2}$ & $+\frac{k \Delta t}{2}$ & $+\frac{k \Delta t}{2}$ & $*$ \\
\hline
\end{tabular}

be obtained. If random errors are present, the residuals will tend to distribute randomly about $+(k \Delta t / 2)$ and $-(k \Delta t / 2)$ providing a bimodal distribution.

If such a bimodal residual distribution is broken down into two distributions, one obtained from first comparisons and the other from the second comparisons in an intercomparison test, the medians of these two distributions will fall at $+(k \Delta t / 2)$ and $-(k \Delta t / 2)$ respectively. That such a separation between the medians of the residual distributions of the first and second comparisons evidences an inhomegeneity in the data brought about by an asymmetry in the actual handling of the blocks in each pair can be seen from the following example. Consider three blocks $A, B$, and $C$ of actual lengths, $a, b$, and $c$ respectively. Let these blocks be compared according to the following intercomparison schedule:
1. $B$ minus $A$.
2. $A$ minus $B$.
3. $A$ minus $C$.
4. $C$ minus $A$.
5. $C$ minus $B$.
6. $B$ minus $C$.

Assume that there is some variation or asymmetry in the handling of the gage blocks which causes each pair to have its correct length difference in the first comparison of each pair, but to appear to have a length difference departing from this correct value by an amount $\alpha \Delta t$ in the second comparison of each pair. Then the observed values obtained from the comparisons should be those shown in table 16 , where the number of each comparison is also given by the circled figures on the chart.
TABLE 16. Observed values which would be obtained in an intercomparison test affected by consistent asymmetrical handling of the gage blocks

\begin{tabular}{c|c|c|c}
\hline \hline Blocks & $A$ & $B$ & $C$ \\
\cline { 1 - 2 }$A$ & $*$ & (1) $b-a$ & (4) $c-a+\alpha \Delta t$ \\
$B$ & (2) $a-b+\alpha \Delta t$ & $*$ & (5) $c-b$ \\
$C$ & (3) $a-c$ & (6) $b-c+\alpha \Delta t$ & $*$ \\
\hline
\end{tabular}

Applying the first step in the least squares method of solution, that is dividing by two the alegebraic difference of comparisons symmetrical to the diagonal, gives what might be called adjusted observed values for each comparison. Thus for comparison 1, an adjusted observed value would be obtained by subtracting the observed value for comparison 2 (the comparison which is diagonally symmetrical to comparison 1) from the observed value for comparison 1 ; e.g., $(b-a)-(a-b+\alpha \Delta t)$ and then dividing this by two,

$$
\frac{(b-a)-(a-b+\alpha \Delta t)}{2}=\frac{2 b-2 a-\alpha \Delta t}{2}
$$

This value for comparison 1 and the adjusted observed values for the other five comparisons are given in table 17 which also illustrates the next step in the calculations. The columns are summed as indicated and these summations are divided by the number of gage blocks to give column footings. Next, a calculated result for each comparison is computed by subtracting the column footings one from another. Thus, the calculated result for comparison 1, the $B$ minus $A$ comparison, is obtained by subtracting the column footing of column $A$ from that of column $B$; e.g.,

$$
\left(\frac{2 b-a-c}{3}\right)-\left(\frac{2 a-b-c}{3}\right)=b-a .
$$

TABLE 17. Adjusted observed values calculated from data in tabie 16

\begin{tabular}{c|c|c|c}
\hline \hline Blocks & $A$ & $B$ & $C$ \\
\hline$A$ & $*$ & $\frac{11}{2 b-2 a-\alpha \Delta t}$ & $\frac{2 c-2 a+\alpha \Delta t}{2}$ \\
$B$ & $\frac{2}{2}$ & $\frac{2 a-2 b+\alpha \Delta t}{2}$ & $\frac{2 c-2 b-\alpha \Delta t}{2}$ \\
$C$ & $\frac{3}{2} \frac{2 a-2 c-\alpha \Delta t}{2}$ & $\frac{62 b-2 c+\alpha \Delta t}{2}$ & $*$ \\
\hline$\Sigma$ & $\frac{2 a-b-c}{3}$ & $\frac{2 b-a-c}{3}$ & $\frac{2 c-a-b}{3}$ \\
\hline$\Sigma / 3$ & $\frac{2 b-a-c}{2 c-a-b}$ \\
\hline
\end{tabular}

These calculated results are shown in table 18. The residuals are then obtained by subtracting the calculated result for any comparison (table 18) from the adjusted observed value for that comparison 
TABLE 18. Calculated results obtained from data in table 17

\begin{tabular}{c|c|c|c}
\hline \hline Blocks & $A$ & $B$ & $C$ \\
\hline$A$ & $*$ & (1) $b-a$ & (1) $c-a$ \\
$B$ & (2) $a-b$ & $*$ & (5) $c-b$ \\
$C$ & (3) $a-c$ & (6) $b-c$ & $*$ \\
\hline
\end{tabular}

TABLE 19. Residuals obtained from data in tables 17 and 18

\begin{tabular}{c|c|c|c}
\hline \hline Blocks & $A$ & $B$ & $C$ \\
\hline$A$ & $*$ & (1) $-\frac{\alpha \Delta t}{2}$ & (4) $+\frac{\alpha \Delta t}{2}$ \\
$B$ & (2) $+\frac{\alpha \Delta t}{2}$ & $*$ & (5) $-\frac{\alpha \Delta t}{2}$ \\
$C$ & (3) $-\frac{\alpha \Delta t}{2}$ & (6) $+\frac{\alpha \Delta t}{2}$ & $*$ \\
\hline
\end{tabular}

(table 17). Thus the residual for comparison 1 would be given in this case by:

$$
\left(\frac{2 b-2 a-\alpha \Delta t}{2}\right)-(b-a)=-\frac{\alpha \Delta t}{2} .
$$

The residuals for these comparisons are given in table 19 together with the number of the comparison.

It should be noted from the comparison schedule that comparisons 1,3 , and 5 are first comparisons on each pair of blocks involved while comparisons 2,4 , and 6 are, in each case, second comparisons. From the residuals obtained, it can be seen that each first comparison gives a residual of $-(\alpha \Delta t / 2)$, while each second comparison gives a residual of $+(\alpha \Delta t / 2)$.
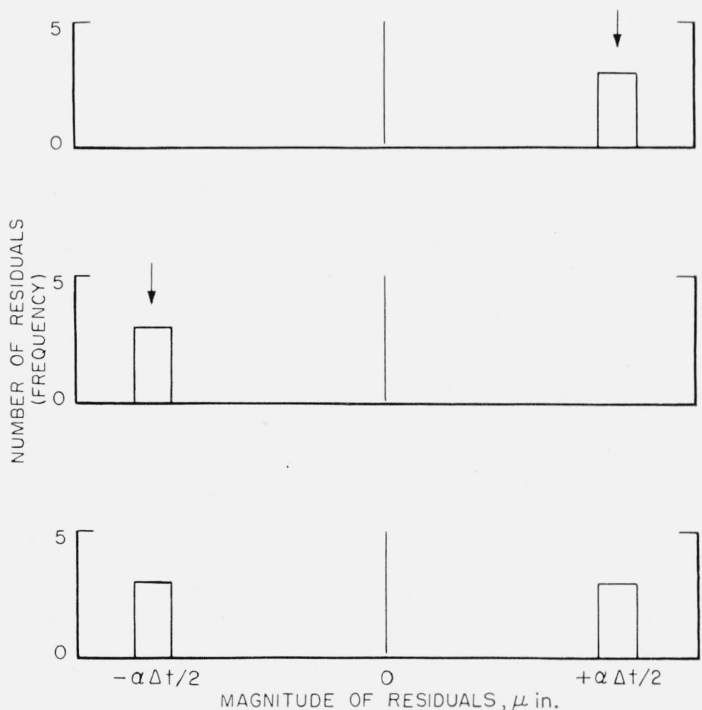

FIGURE 20. Frequency distribution of residuals which would be obtained in an intercomparison test if the comparisons of lengths are affected only by a consistent asymmetrical handling of the gage blocks.
The residual distributions when plotted appear as in figure 20 where the total distribution is plotted at the bottom, the residuals from the first comparisons in the center distribution, and the residuals from the second comparisons in the distribution at the top of the figure. The split between the medians of the first and second comparison distributions which are indicated by the arrows is very apparent and is evidence of an asymmetry in the handling of the gage blocks.

\section{References}

[1] F. H. Rolt, Gages and fine measurements, Vol. 1, (Macmillan \& Co. Ltd., London, England, 1929).

[2] W. B. Emerson, Secular length changes of gage blocks during twenty-five vears, metrology of gage blocks, NBS. Cire. 581, 71, (1957).

[3] F. C. Victory, Dimensional instability in gage blocks, metrology of gage blocks, NBS Circ. 581, 81 (1957).

[4] H. Scott, Dimensional changes accompanying the phenomena of tempering and aging tool steels, Trans. Am. Soc. Steel Treating, 9, 277 (1926).

[5] S. G. Fletcher, and M. Cohen, The dimensional stability of steel, Pt. I-Subatmospheric transformation of retained austenite, Trans. Am. Soc. Metals, 34, 216 (1945).

[6] S. G. Fletcher, B. L. Averbach, and M. Cohen, The dimensional stability of steel, Pt. II-Further experiments on subatmospheric transformation, Trans. Am. Soc. Metals, 40, 703 (1948).

[7] B. L. Averbach, M. Cohen, and S. C. Fletcher, The dimensional stability of steel, Pt. III-Decomposition of martensite and austenite at room temperature, Trans. Am. Soc. Metals, 40, 728 (1948).

[8] B. L. Averbach, and M. Cohen, The isothermal decomposition of martensite and retained austenite, Trans. Am. Soc. Metals, 41, 1024 (1949).

[9] B. S. Lement, B. L. Averbach, and M. Cohen, The dimensional stability of steel, Pt. IV-Tool steels, Trans. Am. Soc. Metals, 41, 1061 (1949).

[10] W. J. Harris, and M. Cohen, Stabilization of the austenite-martensite transformation, Trans. AIME, 180, 447 (1949).

[11] L. E. Gippert, and G. M. Butler, Changes in size and toughness of high carbon-high chromium steels due to subzero treatments, Trans. Am. Soc. Metals, 39, 540 (1947).

[12] A. L. Christenson, Retained austenite and residual stress measurements on certain gage blocks, metrology of gage blocks, NBS Circ. 581, 75 (1957).

[13] National Physical Laboratory, Report on the metrology department for the year 1927, Lab. Rept. 151, (1927).

[14] C. Candler, Modern interferometers, (Hilger and Watts Ltd., London, England, 1951).

[15] J. C. Evans, The determination of thermal lagging times, Proc. Phys. Soc., 59, 242 (1947).

[16] T. R. Young, Achromatic interferometer for gage block comparison, NBS Circ. 581, 43 (April 1957) and Gage block comparator, NBS Tech. News Bull. 40, 176 (December 1956).

[17] W. Kösters, Der gegenwärtige Stand der Meter-Definition, des Meteranschlusses und seine internationale Bedeutung für Wissenschaft und Technik, Werkstattstichnik in Werksleiter 32, 527 (1938).

[18] B. Page, Calibration of meter line standards of length at the National Bureau of Standards, J. Research NBS 54, 1 (1955).

[19] A. L. Christenson, and E. S. Rowland, X-ray measurement of residual stress in hardened high carbon steel, Trans. Am. Soc. Metals, 45, 638 (1953).

[20] A. M. Dexter, Zero point one, ASTE, 59, Book 1, paper 195 (1959). 